\title{
„Refolution“ an der Elbe: Hamburgs neue direkte Demokratie - Die Verfassungsänderungen der Jahre 2008 und 2009 im Kontext
}

\author{
Andreas von Arnauld
}

\section{Abriss der Geschichte direkter Demokratie in Hamburg}

Mit zwei Verfassungsänderungen hat die Bürgerschaft der Freien und Hansestadt Hamburg im Dezember 2008 und Juni 2009 die Volksgesetzgebung ${ }^{1}$ in zentralen Punkten nachdrücklich gestärkt. Manche der Neuregelungen dürften bundesweit einzigartig sein und verdienen daher besondere Aufmerksamkeit. Der Weg der Hansestadt von einem Nachzügler in Sachen direkte Demokratie zu einem Vorreiter und bundesweiten Experimentierfeld ${ }^{2}$ war indes kein gerader. ${ }^{3}$ Die Landesverfassung lässt die Narben von Kontroversen zwischen Bürgerschaft, Senat und Volksinitiativen erkennen, die vor allem während der 18. Legislaturperiode (2004-2008) ausgetragen wurden, in der eine zur Volksgesetzgebung wenig geneigte CDU über die absolute Mehrheit im Landesparlament verfügte. Schon dieser konfliktträchtigen Genese wegen lohnt sich ein Blick zurück.

\section{Zurück in die Zukunft: Der Weg zur Volksgesetzgebung}

Bereits die Hamburger Verfassung vom 7. Januar 1921 enthielt plebiszitäre Elemente. ${ }^{4}$ Nach Art. 58 konnten sechzig Abgeordnete die Durchführung eines Referendums über ein Gesetz noch vor dessen Verkündung verlangen (Abs. 1). Zudem konnte ein Zehntel der Stimmberechtigten in einem Volksbegehren ein Gesetz initiieren, das einem Volksentscheid zuzuführen war, sofern die Bürgerschaft den Entwurf nicht unverändert übernahm (Abs. 2). Vom Volksentscheid ausgenommen waren lediglich Abstimmungen über „Besoldungsordnungen und über Abgabegesetze“

1 Für Hamburg ist der Begriff eigentlich zu eng gewählt, da die Verfassung nicht nur die Möglichkeit vorsieht, über Gesetzesentwürfe abzustimmen, sondern auch über „,andere Vorlagen“. Wenn hier von „Volksgesetzgebung“ die Rede ist, geschieht dies also pars pro toto.

2 Frank Decker, Parlamentarische Demokratie versus Volksgesetzgebung. Der Streit um ein neues Wahlrecht in Hamburg, ZParl 38 (2007), S. 118-133 (120) (,vom Schlusslicht zum Vorreiter der Demokratisierung“); Johannes Rux, Direkte Demokratie in Deutschland, 2008, S. 847 (,Experimentierfeld für einen weiteren Ausbau der unmittelbaren Mitwirkungs- und Entscheidungsbefugnisse der Bürger"). Siehe auch Peter Neumann, Sachunmittelbare Demokratie, 2009, Rn. 87, 89-103.

$3 \mathrm{Zu}$ der Entwicklung näher Andreas Fraude, Direkte Demokratie in Hamburg, in: Andreas Kost (Hrsg.), Direkte Demokratie in den deutschen Ländern, 2005, S. 113-132; Rux, Demokratie (Fn. 2), S. 789-802.

$4 \mathrm{Zu}$ den Landesverfassungen in Weimarer Zeit im Überblick Hanns-Jürgen Wiegand, Direktdemokratische Elemente in der deutschen Verfassungsgeschichte, 2006, S. 44-48; Rux, Demokratie (Fn. 2), S. 130-143. 
(Abs. 3). Im Volksentscheid genügte regelmäßig die Mehrheit der abgegebenen Stimmen; ${ }^{5}$ Verfassungsänderungen musste die Mehrheit der Stimmberechtigten zustimmen (Art. 55 Abs. 2). Die Verfassung von 1921 wurde durch das Reichsgesetz über die Verfassung und Verwaltung der Hansestadt Hamburg vom 9. Dezember 1937 außer Kraft gesetzt, durch das Hamburg seine staatliche Selbständigkeit vorübergehend einbüßte.

Die Nachkriegsverfassung vom 6. Juni 1952 knüpfte weitgehend an die Verfassung von 1921 an. Einer verbreiteten „Plebisphobie der Nachkriegsära“6 entsprechend, verzichtete man aber aus Sorge vor Demagogie auf die Übernahme der direktdemokratischen Elemente bei der Gesetzgebung. ${ }^{7}$ Erhalten blieb dagegen, als eine Hamburger Besonderheit, die Bürgerbeteiligung in der Verwaltung über die sog. Deputationen (Art. 56). ${ }^{8}$ Diese Gremien ehrenamtlich tätiger Bürger, die bei allen Fachbehörden ${ }^{9}$ gebildet werden und unter Vorsitz des Senators tagen, haben ,ihren Ursprung in vordemokratischer Zeit, als es noch darum ging, ,dem selbstherrlichen Regiment des Rates' durch bürgerliche Mitwirkung Grenzen zu ziehen"10. Von der Bürgerschaft für die Dauer der Legislaturperiode aus dem Kreis der zu den Bezirksversammlungen wählbaren Einwohnerinnen und Einwohner gewählt ( 7 Abs. 2 HmbVwBehG), hat sich auch hier die Parteiendemokratie durchgesetzt: Die Deputationen bilden faktisch die Fraktionsstärken in der Bürgerschaft ab und erscheinen heute mehr als ,,verlängerte Arme der Bürgerschaft in den Fachbehörden“11. Eine weitere „Hamburgensie“ ist die Beteiligung von Bürgern an Verwaltungskommissionen, namentlich der Kommission für Bodenordnung und der Kre-

5 Nach $\S 13$ Abs. 1 S. 1 des Gesetzes über den Volksentscheid und das Volksbegehren im hamburgischen Staate v. 18.2.1921, GVB1. 1921, S. 101.

6 Rudolf Steinberg, zitiert nach Wolfgang Luthardt, Probleme und Perspektiven direkter Demokratie in Deutschland, APuZ 14/1997, S. 13-22 (18). Kritisch zu dieser ,vorübergehenden plebiszitären Quarantäne“ und ihren Gründen Neumann, Demokratie (Fn. 2), Rn. 652 m.w.N. in Fn. 24. Siehe auch Hans Herbert v. Arnim, Vom schönen Schein der Demokratie, 2000, S. 179-181. Eingehend zu den Hintergründen Otmar Jung, Grundgesetz und Volksentscheid: Gründe und Reichweite der Entscheidungen des Parlamentarischen Rats gegen Formen direkter Demokratie, 1994; Wiegand, Elemente (Fn. 4), S. 185-236.

7 Rux, Demokratie (Fn. 2), S. 789 m.w.N.

8 Näher dazu Hans Peter Bull, Mitwirkung des Volkes an der Verwaltung durch die Deputationen der Hamburger Fachbehörden, in: FS für Hans Peter Ipsen, 1977, S. 299-321; Klaus David, Bürgerbeteiligung in der Hamburger Verwaltung - eine lange Tradition, in: Hans Peter Bull (Hrsg.), Fünf Jahre direkte Bürgerbeteiligung in Hamburg, 2001, S. 40-50; Frank Hinrichs, Die Deputationen in der hamburgischen Verwaltung, VR 2006, S. 305-308. Empirisch untersucht bei Joachim von Hein, Bürgerbeteiligung an der Leitung einer Großstadtverwaltung, 1985.

9 Fachbehörden in Hamburg entsprechen in Flächenstaaten den Ministerien; wegen der fehlenden Trennung staatlicher und gemeindlicher Aufgaben kann allerdings der Senat jederzeit Bezirksangelegenheiten an sich ziehen (sog. Evokationsrecht, § $42 \mathrm{HmbBezVwG).}$

10 Hans-Joachim Koch, Die Verfassungsentwicklung in Hamburg, JöR 51 (2003), S. 251-270 (267).

11 So kritisch Koch, Verfassungsentwicklung (Fn. 10), S. 267. 
ditkommission, die u.a. über die Übernahme von Landesbürgschaften entscheidet. ${ }^{12}$

Eine Beteiligung an der Landesgesetzgebung wurde den Bürgerinnen und Bürgern jedoch erst 1996 wieder ermöglicht. Vorausgegangen war die gesamtdeutsche Debatte über die Einführung plebiszitärer Elemente in das Grundgesetz (und in jene Landesverfassungen, die sie noch nicht kannten) sowie, als lokaler Impuls, der Hamburger Diätenskandal vom Herbst 1991. Die in Reaktion hierauf eingesetzte Enquête-Kommission „Parlamentsreform“ unter dem Vorsitz des späteren Justizsenators und Bundesverfassungsrichters Wolfgang Hoffmann-Riem wurde, ohne dass die direkte Demokratie von vornherein auf der Tagesordnung gestanden hätte, zur „Wegbereiterin für die Etablierung direktdemokratischer Elemente auf Landesebene“. ${ }^{13}$ Weitere politische Turbulenzen, namentlich das vorzeitige Ende der 14. Bürgerschaft nach dem Urteil des Hamburgischen Verfassungsgerichts 1993 und die Bildung einer Koalitionsregierung aus SPD und der neu gegründeten STATT-Partei, verzögerten freilich die Umsetzung der Vorschläge. Als letztes Bundesland führte die Freie und Hansestadt Hamburg schließlich mit Verfassungsänderung vom 29. Mai 1996 Plebiszite auf Landesebene ein. Nach Art. 48 HmbV werden Gesetzesvorlagen seitdem ,vom Senat, aus der Mitte der Bürgerschaft oder durch Volksbegehren eingebracht“ (Abs. 1), die Gesetze „,von der Bürgerschaft oder durch Volksentscheid beschlossen“"(Abs. 2). Zentrale Bestimmung wurde der neu gefasste Art. 50:

\section{Artikel 50}

(1) Das Volk kann im Rahmen der Zuständigkeit der Bürgerschaft den Erlaß, die Änderung oder die Aufhebung eines Gesetzes beantragen. Einzelvorhaben, Bauleitpläne und vergleichbare Pläne, Haushaltsangelegenheiten, Abgaben, Tarife der öffentlichen Unternehmen sowie Dienst- und Versorgungsbezüge können nicht Gegenstand einer Volksinitiative sein. Die Volksinitiative ist zustande gekommen, wenn mindestens 20.000 zur Bürgerschaft Wahlberechtigte den Gesetzentwurf unterstützen.

(2) Der Senat führt das Volksbegehren durch, sofern die Bürgerschaft nicht innerhalb von vier Monaten nach Einreichung der Unterschriften ein dem Anliegen der Volksinitiative entsprechendes Gesetz verabschiedet hat. Das Volksbegehren ist zustande gekommen, wenn es von einem Zehntel der Wahlberechtigten unterstützt wird.

(3) Entspricht die Bürgerschaft nicht binnen drei Monaten dem Volksbegehren, so legt der Senat den Gesetzentwurf dem Volk zur Entscheidung vor. Die

$12 \mathrm{Zu}$ diesen und weiteren Mitwirkungsformen David, Bürgerbeteiligung (Fn. 8). Kritisch Koch, Verfassungsentwicklung (Fn. 10), S. 267 f.

13 Fraude, Hamburg (Fn. 3), S. 117. Zu den Hintergründen der Verfassungsreform von 1996 Peter Unruh, Zum Stand der Verfassungsreform in Hamburg, DÖV 1995, S. 265-275. Speziell zur Volksgesetzgebung: Bericht der Enquête-Kommission „Parlamentsreform“, Hamburgische Bürgerschaft, Drs. 14/2600 v. 20.10.1992, Bd. 10, S. 218-227; Ulrich Karpen/Thies Bösling, Volksgesetzgebung als Kernbestandteil der Verfassungsreform 1996, in: Bull, Bürgerbeteiligung (Fn. 8), S. 68-76; Rux, Demokratie (Fn. 2), S. 789-792. 
Bürgerschaft kann einen eigenen Gesetzentwurf beifügen. Ein Entwurf ist angenommen, wenn die Mehrheit der Abstimmenden und mindestens ein Viertel der Wahlberechtigten zustimmen. Bei Verfassungsänderungen müssen zwei Drittel derjenigen, die ihre Stimme abgegeben haben, mindestens jedoch die Hälfte der Wahlberechtigten, zugestimmt haben.

(4) Ein durch Volksentscheid angenommenes Gesetz kann innerhalb von zwei Jahren nicht im Wege von Volksinitiative, Volksbegehren und Volksentscheid geändert werden.

(5) Während eines Zeitraumes von drei Monaten vor dem Tag einer allgemeinen Wahl in Hamburg finden keine Volksbegehren und Volksentscheide statt.

(6) Das Hamburgische Verfassungsgericht entscheidet auf Antrag des Senats, der Bürgerschaft, eines Fünftels der Abgeordneten der Bürgerschaft oder der Volksinitiatoren über die Durchführung von Volksbegehren und Volksentscheid. Volksbegehren und Volksentscheid ruhen während des Verfahrens.

(7) Das Gesetz bestimmt das Nähere. Es kann auch Zeiträume bestimmen, in denen die Fristen nach Absatz 2 Satz 1 und Absatz 3 Satz 1 wegen sitzungsfreier Zeiten der Bürgerschaft nicht laufen.

Damit orientierte sich Hamburg an dem schon in anderen Bundesländern etablierten Modell einer Volksgesetzgebung, in der die Initiative selbst beim Volk liegt; ein Referendum, d.h. die Abstimmung über eine parlamentarische Gesetzesvorlage wurde nicht eingeführt (allerdings steht der Bürgerschaft das Recht zu, eine Konkurrenzvorlage dem Volksentscheid zu unterbreiten). ${ }^{14}$ Das gewählte Modell ist ein dreistufiges, in dem die Volksinitiative auf erster Stufe automatisch zu einem Volksbegehren (zweite Stufe) führt, falls die Bürgerschaft dem Entwurf der Initiative nicht binnen vier Monaten entspricht. Ist das Volksbegehren erfolgreich und übernimmt die Bürgerschaft den Entwurf noch immer nicht, kommt es schließlich auf dritter Stufe zum Volksentscheid. ${ }^{15}$ Für diesen sah die Verfassungsänderung von 1996 vor, dass die Mehrheit für den Entwurf zugleich mindestens einem Viertel der Stimmberechtigten entsprechen müsse. Bei Verfassungsänderungen wurde die Mehrheit auf zwei Drittel der abgegebenen Stimmen und mindestens die Hälfte der Wahlberechtigten festgesetzt. Die Ausgestaltung erfolgte im Gesetz über Volksinitiative, Volksbegehren und Volksentscheid (HmbVVVG), das 2005 in Volksabstimmungsgesetz (HmbVAbstG) umbenannt wurde. ${ }^{16}$ Flankiert wurde die Volksgesetzgebung

$14 \mathrm{Zu}$ diesen Grundtypen plebiszitärer Demokratie v. Arnim, Schein (Fn. 6), S. 204 f.; Otmar Jung, Grundsatzfragen der direkten Demokratie, in: Kost, Direkte Demokratie (Fn. 3), S. 312-366 (315); Neumann, Demokratie (Fn. 2), Rn. 251-254. Siehe ferner Frank Decker, Direkte Demokratie im deutschen „Parteienbundesstaat“, APuZ 10/2006, S. 3-9 (4), auf S. 7 auch zur konsensdemokratischen Drift solcher Modelle. Für Deutschland zweifelnd Raphael Magin/Christina Eder/Adrian Vatter, Direkte Demokratie in den Bundesländern, in: Achim Hildebrandt u.a. (Hrsg.), Die Politik der Bundesländer, 2008, S. 345-362 (359).

$15 \mathrm{Zu}$ den zwei- und dreistufigen Modellen vertiefend Neumann, Demokratie (Fn. 2), Rn. 255-320.

16 Gesetz v. 20.6.1996, GVB1. 1996, S. 136, zuletzt geändert am 16.12.2008, GVB1. 2008, S. 439. 
durch das Institut einer Volkspetition in Art. $25 \mathrm{c}$ (heute Art. 29). ${ }^{17}$ Danach befasst sich die Bürgerschaft mit dem Anliegen von Petenten, die durch die Unterschrift von 10.000 Einwohnern unterstützt werden, und gibt einem Vertreter der Petenten Gelegenheit, das Anliegen in einem Ausschuss zu erläutern. Hierdurch wurde ein Pendant zur Volksinitiative in Bundesländern geschaffen, die ein zweistufiges Modell der Volksgesetzgebung gewählt haben (wie z.B. Berlin oder Thüringen) und in denen die Volksinitiative nicht automatisch zu einem Volksbegehren führt.

Ein umfangreicher Ausschlusskatalog in Art. 50 Abs. 1 HmbV 1952/1996, ein Quorum von $10 \%$ der Stimmberechtigten für das Volksbegehren (das nach dem HmbVVVG innerhalb von 14 Tagen durch Eintragung auf Ämtern erzielt werden musste), hohe Quoren beim Volksentscheid, die namentlich bei Verfassungsänderungen prohibitiv wirken mussten - all dies führte dazu, dass die Hamburger Regelung schon bald als unzureichend kritisiert wurde. ${ }^{18}$ Es formierte sich die Volksinitiative „Forum Bürgerinnen- und Bürgerbewegung - Verein zur Förderung von Demokratie und Bürgerbeteiligung“, später „Mehr Demokratie in Hamburg“, die sich im November 1997 dem bundesweit agierenden Verein „Mehr Demokratie“ als Landesverband anschloss. Während sich die GAL frühzeitig mit der Initiative solidarisierte, kamen Widerstände vor allem aus SPD und CDU. Bezeichnenderweise waren die beiden ersten Volksinitiativen unter dem neuen Art. $50 \mathrm{HmbV}$ auf eine Stärkung direktdemokratischer Partizipation gerichtet. Die Initiativen „Für erleichterte Volksentscheide in Hamburg" und „Für Bürgerentscheide in Bezirken“ führten im März 1998 zu zwei erfolgreichen Volksbegehren. Beim Volksentscheid am 27. September 1998 erzielte der Entwurf zu den Bürgerentscheiden 73,24\% der abgegebenen Stimmen, entsprechend 44,84\% der Stimmberechtigten, und nahm damit klar die Hürden für ein einfaches Gesetz nach Art. 50 Abs. 3 S. 3 HmbV. ${ }^{19}$ Mit 74,05 \% der abgegeben Stimmen und 45,5\% Zustimmung aller Wahlberech-

17 Dazu näher Rux, Demokratie (Fn. 2), S. 802-804.

18 Michael Efler, Der Kampf um „Mehr Demokratie in Hamburg“, in: Bull, Bürgerbeteiligung (Fn. 8), S. 77-87 (77 f.) (,Volksgesetzgebung, light““). Siehe auch Decker, Demokratie (Fn. 2), S. 121: ,,bewegte sich ..., was die Anwenderfreundlichkeit angeht, im Mittelfeld aller Bundesländer".

19 Die Bürgerbeteiligung in den Hamburger Bezirken kann hier aus Platzgründen nicht ebenfalls behandelt werden. Siehe dazu eingehend Andreas Dressel, Bürgerbegehren und Bürgerentscheid in den Hamburger Bezirken, 2003. Ferner ders., Bürgerbegehren und Bürgerentscheid in den Hamburger Bezirken - eine Zwischenbilanz, in: Theo Schiller/Volker Mittendorf (Hrsg.), Direkte Demokratie: Forschung und Perspektiven, 2002, S. 231-248; Karsten Vollrath, Die direktdemokratische Praxis in den Hamburger Bezirken: Zwischen Konsenssuche und administrativer Sabotage, ebd., S. 249-260; Beiträge in Bull, Bürgerbeteiligung (Fn. 8) von: Andreas Dressel, S. 102-128; Hartmut Falkenberg/Ernst Heilmann, S. 129-141; Karsten Vollrath, S. 142-150; Ingo Egloff/Gerhard Fuchs, S.151-162; Hans-Peter Strenge, S. 163-168. Zu einer weiteren Hamburgensie, den ,zugewählten Bürgern“ in den Ausschüssen der Bezirksversammlungen (§ 17 Abs. 3 S. 1 und 2 HmbBezVG) Fraude, Hamburg (Fn. 3), S. 126. 
tigten verfehlte der andere Entwurf hingegen knapp das $50 \%$-Quorum für Verfassungsänderungen in Art. 50 Abs. $3 \mathrm{~S} .4 \mathrm{HmbV} .{ }^{20}$

Trotz des Scheiterns der erstrebten Verfassungsänderung wurde das klare Signal von den politischen Eliten der Hansestadt erkannt. Nach einigen inner- und zwischenparteilichen Querelen überwanden SPD und CDU schließlich ihre Skepsis gegenüber der Volksgesetzgebung und brachten gemeinsam mit der GAL einen interfraktionellen Entwurf in die Bürgerschaft ein. ${ }^{21}$ Am 16. Mai 2001 beschloss diese mehrere markante Änderungen von Art. $50 \mathrm{HmbV}:{ }^{22}$

- die Erweiterung um andere „,bestimmte Gegenstände der politischen Willensbildung" (,,andere Vorlagen“) jenseits der Gesetzgebung;

- die Streichung des Ausschlusses von Einzelvorhaben, Bauleitplänen und vergleichbaren Plänen;

- die Absenkung der erforderlichen Unterschriftenzahl für die Volksinitiative von 20.000 auf 10.000 ;

- die ausdrückliche Aufnahme eines Entscheidungsrechts der Volksinitiatoren, ob sie die Durchführung eines Volksbegehrens bzw. eines Volksentscheides beantragen oder ihre Vorlage zurücknehmen wollen;

- die Absenkung des Zustimmungsquorums für das Volksbegehren von $10 \%$ auf $5 \%$ der Wahlberechtigten;

- die Absenkung des Zustimmungsquorums für Volksentscheide von $25 \%$ auf $20 \%$ der Wahlberechtigten bei einfachen Gesetzen oder anderen Vorlagen.

Sieht man von der Beibehaltung der hohen Hürde für Verfassungsänderungen ab, besaß Hamburg nun eine der bundesweit plebiszitfreundlichsten Regelungen und wurde insoweit nur noch von Bayern übertroffen. ${ }^{23}$ Auch das HmbVVVG erfuhr wichtige Änderungen: So wurde eingeführt, dass finanzwirksame Initiativen von

20 Die hohe Beteiligungsquote konnte nur durch Kopplung mit der Bundestagswahl 1998 erreicht werden. Allerdings war es im Vorfeld zu Unregelmäßigkeiten gekommen. So war die Informationspolitik unzureichend, Abstimmungsunterlagen wurden verzögert und erst weit nach den Wahlunterlagen versandt: Rux, Demokratie (Fn. 2), S. 798 f.

21 Den turbulenten Weg zur Verfassungsänderung beschreiben näher Efler, Kampf (Fn. 18) und Martin Schmidt, Die politische Debatte um eine Reform der Volksgesetzgebung 1997/98 aus der Sicht der Hamburgischen Bürgerschaft, in: Bull, Bürgerbeteiligung (Fn. 8), S. 88-95. Siehe ferner Rux, Demokratie (Fn. 2), S. 792-800; Neumann, Demokratie (Fn. 2), Rn. 90-92.

22 Rückblickend zu den Verfassungsreformen von 1996 und 2001 Koch, Verfassungsentwicklung (Fn. 10), S. 251-270, insb. S. 254, 265 f.; zur Verfassungsreform von 2001 Rolf-Dieter Klooß, Die Reform der Volksgesetzgebung 2001: Niedrigere Quoren und mehr Verfahrensflexibilität, in: Bull, Bürgerbeteiligung (Fn. 8), S. 96-100.

23 Zum Volksentscheid-Ranking des Vereins „Mehr Demokratie“ Ralph Kampwirth, Volksentscheide in Deutschland: Bayern Spitze, Berlin Schlusslicht, in: FS für Hans Herbert von Arnim, 2004, S. 367-373 (Hamburg hinter Bayern auf Platz 2 mit der Gesamtnote 2,55, auf ,Gemeindeebene" mit der Note 1,5 sogar auf dem 1. Platz). Eingehender Vergleich bei Bärbel Martina Weixner, Direkte Demokratie in den Bundesländern, 2002, S. 73-264. Näher auch dies., Direkte Demokratie in den Bundesländern, APuZ 10/2006, S. 18-24; Magin/Eder/Vatter, Demokratie (Fn. 14), S. 345-362. 
einem Vorschlag zur Kostendeckung begleitet sein sollen (§ 3 Abs. 2); auch wurden nach den Erfahrungen mit den ersten Volksentscheiden Regelungen zur verbesserten Information der Stimmberechtigten getroffen. ${ }^{24}$

\section{Von 2001 bis 2008: Die Zeit der Konflikte}

Die Bürgerschaftswahlen vom 31. Oktober 2001 brachten das Ende der rot-grünen Koalition, die Hamburg die vergangenen vier Jahre regiert hatte. Die CDU unter Ole von Beust bildete nun eine Regierung gemeinsam mit der FDP und der rechtspopulistischen „Partei Rechtsstaatliche Offensive“. Der politische Richtungswechsel provozierte eine Reihe von „oppositionellen“ Volksinitiativen, die Korrekturen der Politik des neuen Senats anstrebten. ${ }^{25}$ Die schwelenden Konflikte zwischen Bürgerschaft und Volksinitiatoren traten allerdings erst 2004 offen zutage, nachdem die CDU in den vorgezogenen Bürgerschaftswahlen vom 29. Februar 2004 die absolute Mehrheit errungen hatte. Zwischen Senat und Bürgerschaft auf der einen sowie den Volksinitiatoren auf der anderen Seite gab es zwei miteinander verbundene Konfliktlinien: eine sachbezogene und eine verfahrensbezogene.

\section{a) Sachebene}

Auf der Sachebene waren es zwei Fälle, in denen Senat und Bürgerschaft ohne Wahrung einer politischen "Schamfrist“ Volksentscheiden zuwider handelten, die zur offenen Konfrontation führten. Der erste Fall betraf die vom CDU-geführten Senat betriebene Privatisierung des Landesbetriebs Krankenhäuser (LBK). Hiergegen wandte sich die Volksinitiative „Gesundheit ist keine Ware“. Auf das Volksbegehren im Mai 2003 folgte am 29. Februar 2004 ein Volksentscheid, bei dem $76,8 \%$ der Abstimmenden der Vorlage zustimmten. Dies entsprach (bei einer Beteiligung von 64,9\%) einer Zustimmungsquote von 49,2 \% aller Stimmberechtigten. Der Volksbeschluss forderte den Senat auf sicherzustellen, dass die Freie und Hansestadt Hamburg Mehrheitseigentümerin des LBK und seiner Einrichtungen bleibe. Am 7. September 2004 legte der Senat der Bürgerschaft einen Gesetzesentwurf über eine Privatisierung des LBK zu 74,9\% vor. ${ }^{26}$

Die Vertreter der Volksinitiative riefen das Landesverfassungsgericht an, das den Antrag am 15. Dezember 2004 als zulässig, aber unbegründet zurückwies. ${ }^{27}$ Die

24 Dazu Klooß, Reform (Fn. 22), S. 99 f. Vertiefend zur Rechtslage ab 2001 bei Stephan Stüber, Volksabstimmungen in Hamburg, NordÖR 2002, S. 227-234. Siehe auch Fraude, Hamburg (Fn. 3), S. 119-121; Rux, Demokratie (Fn. 2), S. 804-822.

25 Eingehende Darstellung aller Initiativen bis Ende 2007 bei Rux, Demokratie (Fn. 2), S. 822-844.

26 Fraude, Hamburg (Fn. 3), S. 128; Rux, Demokratie (Fn. 2), S. 827 f.

27 HmbVerfG, Urt. v. 15.12.2004, HVerfG 6/04 (LBK II), NVwZ 2005, S. 685. Siehe zuvor schon im einstweiligen Rechtsschutz Urt. v. 15.12.2003, HVerfG 4/03 (LBK I), juris, Rn. 36-38. Krit. Hans Peter Bull, Der Volksentscheid: unverbindlich und folgenlos?, NordÖR 2005, S. 99-101. 
„andere Vorlage“ habe nur eine Aufforderung an den Senat enthalten, die - ähnlich einem parlamentarischen Ersuchen - keine Verbindlichkeit besitze. Zudem sei diese Aufforderung nur an den Senat, nicht an die Bürgerschaft gerichtet gewesen, die letztlich über den Verkauf zu entscheiden hätte. In einem obiter dictum fügte das Gericht hinzu, dass selbst wenn die Vorlage rechtsverbindliche Wirkung besäße, die Bürgerschaft jederzeit von dem Ergebnis eines Volksentscheides abweichen dürfe. Volksgesetzgebung und parlamentarische Gesetzgebung seien gleichrangig; eine Sperrwirkung gebe es nicht. Grenzen errichte allenfalls der Grundsatz der Organtreue.

Der zweite Konflikt über eine Sachfrage betraf eine Änderung des Wahlrechts. Hier bestand auch inhaltlich große Nähe zu Fragen der direkten Demokratie, weil die Volksinitiative „Mehr Bürgerrechte - Ein neues Wahlrecht für Hamburg“ eine Wahlrechtsnovelle vorschlug, die den Wählerinnen und Wählern größere Möglichkeiten einräumen sollte, gewissermaßen an den Parteilisten vorbei auf die personelle Zusammensetzung von Bürgerschaft und Bezirksversammlungen Einfluss zu nehmen. ${ }^{28}$ Der Volksentscheid am 13. Juni 2004 erbrachte $66,7 \%$ Zustimmung zu dem Entwurf der Initiative (entsprechend 21,1 \% aller Wahlberechtigten). Der Senat kritisierte das volksbeschlossene Wahlrecht als zu kompliziert und als Überforderung der Wähler und nahm noch in derselben Legislaturperiode eine Änderung des Wahlgesetzes in Angriff. ${ }^{29}$ Bevor das volksbeschlossene Wahlrecht erstmals zur Anwendung kommen konnte, wurde, kritisch begleitet von der Kampagne „Ole spielt falsch“, das HmbBüWG von der Bürgerschaft am 12. Oktober 2006 grundlegend reformiert. ${ }^{30}$

Erwartungsgemäß sah das Hamburgische Verfassungsgericht in dieser parlamentarischen „Konterlegislatur“31 keinen Verfassungsverstoß. ${ }^{32}$ In seinem Urteil vom 25. April 2007 knüpfte es an das obiter dictum im LBK-Urteil an und bestätigte,

28 Dazu näher Ulrich Ramsauer/Maren Heidmann, Ein neues Wahlrecht für Hamburg?, NordÖR 2003, S. 482-485; Fraude, Hamburg (Fn. 3), S. 122-125, 127. Zu Verbindungslinien zur direkten Demokratie vgl. allgemein v. Arnim, Schein (Fn. 6), S. 258-271.

29 Dazu kritisch Decker, Demokratie (Fn. 2), S. 118-133; Ernst Gottfried Mahrenholz, Zur Änderung des durch Volksbegehren angenommenen Hamburgischen Wahlrechts in derselben Wahlperiode, NordÖR 2007, S. 11-18; ders., Legislative Konkurrenzen, in: FS für Hans-Peter Schneider, 2008, S. 210-222 (218-220); Rux, Demokratie (Fn. 2), S. 828-832.

$30 \mathrm{HmbGVB1}$. 2006, S. 519. Unverändert blieb u.a. die im Volksentscheid ebenfalls beschlossene Zusammenlegung des Termins der Bezirksversammlungen mit demjenigen der Wahlen zum Europäischen Parlament. Zu der Frage, ab welcher Wahl diese Regelung greifen kann, Franziska Lantz, Termin der Bezirksversammlungswahl nach dem Volksentscheid „Mehr Bürgerrechte - Ein neues Wahlrecht für Hamburg“, NordÖR 2005, S. 192-201.

31 Begriff nach Otmar Jung, Volksgesetze und parlamentarische Konterlegislatur, in: Klemens H. Schrenk/Markus Soldner (Hrsg.), Analyse demokratischer Regierungssysteme. FS für Wolfgang Ismayer, 2010, S. 427-442.

32 HmbVerfG, Urt. v. 27.4.2007, HVerfG 4/06 (Wahlrecht II), NordÖR 2007, S. 301. Ein paralleler Antrag der ehemaligen Initiatoren (Urt. v. 26.4.2007, HVerfG 3/06, Wahlrecht I) wurde als unzulässig zurückgewiesen, weil das Gesetzesinitiativrecht mit Durchführung des Volksentscheides gleichsam erloschen sei: NordÖR 2007, S. 312 mit abw. Votum Hardt und v. Paczensky. 
dass wegen der Gleichrangigkeit von Volksgesetzgeber und Bürgerschaft eine Aufhebung volksbeschlossener Gesetze jederzeit möglich sei. Der Grundsatz der Organtreue, der auch nach Abschluss des Volksgesetzgebungsverfahrens fortwirke, fordere aber, „,dass das Parlament bei einer späteren eigenen Beschlussfassung über ein Gesetz nicht leichtfertig über den im Volksentscheid zum Ausdruck gekommenen Willen des Volkes hinweggehen darf, sondern diesen würdigen und danach seine Abwägung vornehmen muss" ${ }^{33}$ Dies indes sei vom Verfassungsgericht nur eingeschränkt zu überprüfen, nämlich darauf, ob ein evidenter Verstoß oder Missbrauch vorliege. Die Richterinnen v. Paczensky und Wirth-Vonbrunn kritisierten in einem Sondervotum die Entwertung der Volksgesetzgebung durch diesen Mehrheitsentscheid. $^{34}$

\section{b) Verfahrensebene}

Die zweite Konfliktlinie betraf das Volksgesetzgebungsverfahren selbst. ${ }^{35}$ Es ist charakteristisch für die Hamburger Entwicklung, dass von Anfang an Volksinitiativen gerade auch auf den weiteren Ausbau direktdemokratischer Elemente zielten. ${ }^{36}$ Nach den Abstimmungsniederlagen beim LBK-Entscheid und dem Volksentscheid über das Wahlrecht war es nun an Senat und Bürgerschaft, sich an eine Änderung des Abstimmungsrechts zu machen, freilich in einschränkender Weise. ${ }^{37} \mathrm{Am}$ 4. Mai 2005 nahm die Bürgerschaft weit reichende Änderungen am HmbVVVG (nunmehr HmbVAbstG) vor. ${ }^{38}$ So wurden für Volksbegehren gesonderte Eintragungsformulare vorgeschrieben und die freie Sammlung von Stimmen durch die Initiatoren ausgeschlossen - angeblich aus Gründen des Datenschutzes und um sozialen Druck auf die Stimmberechtigten auszuschließen. Da die Möglichkeit zur freien Sammlung die Rechtfertigung für die kurze Eintragungsfrist von zwei Wochen war (Art. 42 Abs. 1 S. 5 SchlHV z.B. bestimmt eine Frist von sechs Monaten) ${ }^{39}$, wurde diese um eine Woche verlängert. Volksentscheide sollten von Wahltagen abgekoppelt werden, um, so die offizielle Begründung, der großen Zahl von Abstimmungen organisatorisch Rechnung tragen zu können und um die Eigenständigkeit der Abstimmung auch für die Wählerinnen und Wähler zu verdeutlichen. Dass auf diese Weise Volksentscheide nicht mehr von der Mobilisierungswirkung allgemeiner Wahlen profitieren würden, dürfte sicherlich kein unbeabsichtigter Nebeneffekt gewesen sein. Das bundesweit einmalige Kopplungsverbot wurde vom Hamburgi-

33 A.a.O., S. 304.

34 A.a.O., S. 311. Ebenso Mahrenholz, Konkurrenzen (Fn. 29), S. 220 f.

$35 \mathrm{Zu}$ dieser Selbstbezüglichkeit Decker, Demokratie (Fn. 2), S. 121.

36 Fraude, Hamburg (Fn. 3), S. 122.

37 Rux, Demokratie (Fn. 2), S. 800 f.; zu der sich abzeichnenden Entwicklung bereits Fraude, Hamburg (Fn. 3), S. 129-131, der auf S. 131 daran erinnert, dass die CDU die fraglichen Regelungen 2001 noch mitgetragen hatte.

38 HmbGVB1. 2005, 195. Näher dazu und zu den folgenden Konflikten Neumann, Demokratie (Fn. 2), Rn. 93-103.

39 Vgl. Stüber, Volksabstimmungen (Fn. 24), S. 228 f. 
schen Verfassungsgericht für verfassungswidrig erklärt, da Art. 50 Abs. $5 \mathrm{HmbV}$ nach Wortlaut und Entstehungsgeschichte garantiere, dass Wahltage Abstimmungstage sein könnten. ${ }^{40}$

Kaum überraschend, hatte der Verein „Mehr Demokratie“ die auf dem Weg befindlichen Gesetzesänderungen mit zwei neuen Volksinitiativen beantwortet: Die Initiative „Rettet den Volksentscheid“ zielte im Wesentlichen darauf, die geplanten Restriktionen im HmbVAbstG zu verhindern bzw. aufzuheben, die parallel gestartete Initiative „Hamburg stärkt den Volksentscheid“ hatte eine Verfassungsänderung zum Gegenstand, mit der die direkte Demokratie gestärkt und gegen Übergriffe des Senats und der Bürgerschaft gesichert werden sollte. Das Volksbegehren zu beiden Entwürfen, das im Februar und März 2007 bereits unter den verschärften Bedingungen des novellierten HmbVAbstG stattfand, ${ }^{41}$ war erfolgreich: Beide Vorlagen erhielten rund 100.000 Unterschriften und damit deutlich mehr als die notwendigen 60.747. Überraschend erklärte der Senat sich zur Übernahme des Antrags auf RückÄnderung des HmbVAbstG bereit; ${ }^{42}$ daher musste sich nur noch der Antrag zur Änderung von Art. $50 \mathrm{HmbV}$ dem Volksentscheid stellen. Unter Ausnutzung aller legalen Möglichkeiten hatte der Senat eine Zusammenlegung mit der Bürgerschaftswahl am 24. Februar 2008 verhindert und den Termin auf den 14. Oktober 2007, den Sonntag vor Beginn der Hamburger Schulferien, festgesetzt. Rechtlich problematischer waren rund 200.000 Briefe, die der „Privatmann“ Ole von Beust kurz vor der Abstimmung an Hamburger Haushalte versandt hatte und in denen er sich gegen die Verfassungsänderung aussprach. ${ }^{43}$ Der Entwurf der Initiatoren erhielt schließlich $75,9 \%$ der abgegebenen Stimmen, verfehlte aber zu geringer Beteiligung wegen das Zustimmungsquorum für Verfassungsänderungen.

\section{2008/2009: Die direktdemokratische Wende}

Unmittelbar nach dem Scheitern des Volksentscheids vom 14. Oktober 2007 startete „Mehr Demokratie“ eine weitere Volksinitiative, der eine überarbeite Fassung des letzten Entwurfs zugrunde lag. Die Initiative „Für faire und verbindliche Volksentscheide-Mehr Demokratie“" wurde am 20. Februar 2008 erfolgreich abgeschlossen, acht Tage vor der Bürgerschaftswahl, aus der die bundesweit erste schwarz-grüne Landesregierung hervorgehen sollte. Im Koalitionsvertrag vereinbarten CDU und GAL, gemeinsam mit den Initiatoren zu einer Verfassungsänderung zu kommen, „die die Fortsetzung des von der Volksinitiative angestoßenen Volksgesetzgebungs-

40 HmbVerfG, Urt. v. 31.3.2006, 2/05 (VolXUni II), DVB1. 2006, S. 1590-1593.

41 Zur Frage der Anwendbarkeit auf bereits in Gang gesetzte Volksgesetzgebungsverfahren auch HmbVerfG, Beschluss v. 7.8.2006, HVerfG 3/05, juris.

42 Hamburgische Bürgerschaft, Drs. 18/6341 v. 31.5.2007. Dazu Rux, Demokratie (Fn. 2), S. 801 f., 843 .

$43 \mathrm{Zu}$ den Hintergründen der Initiative und dem weiteren Verlauf näher Jung, Konterlegislatur (Fn. 31), S. 434-440. 
verfahrens überflüssig macht“44 . Bereits Ende des Jahres erfolgte eine grundlegende Verfassungsänderung, ${ }^{45}$ auf die sogleich im Detail einzugehen sein wird und die zum Verzicht auf das Volksbegehren führte. Der neue Art. $50 \mathrm{HmbV}$ lautet nunmehr:

Artikel 50

(1) ${ }^{1}$ Das Volk kann den Erlass, die Änderung oder die Aufhebung eines Gesetzes oder eine Befassung mit bestimmten Gegenständen der politischen Willensbildung (andere Vorlage) beantragen. ${ }^{2}$ Bundesratsinitiativen, Haushaltspläne, Abgaben, Tarife der öffentlichen Unternehmen sowie Dienst- und Versorgungsbezüge können nicht Gegenstand einer Volksinitiative sein. ${ }^{3}$ Die Volksinitiative ist zustande gekommen, wenn mindestens 10.000 zur Bürgerschaft Wahlberechtigte den Gesetzentwurf oder die andere Vorlage unterstützen.

(2) ${ }^{1}$ Die Bürgerschaft befasst sich mit dem Anliegen der Volksinitiative. ${ }^{2} \mathrm{Sie}$ oder ein Fünftel ihrer Mitglieder kann ein Prüfungs- und Berichtsersuchen zu den finanziellen Auswirkungen an den Rechnungshof richten. ${ }^{3}$ Die Volksinitiatoren erhalten Gelegenheit, das Anliegen in einem Ausschuss zu erläutern. ${ }^{4}$ Sofern die Bürgerschaft nicht innerhalb von vier Monaten nach Einreichung der Unterschriften das von der Volksinitiative beantragte Gesetz verabschiedet oder einen Beschluss gefasst hat, der der anderen Vorlage vollständig entspricht, können die Volksinitiatoren die Durchführung eines Volksbegehrens beantragen. ${ }^{5}$ Sie können den Gesetzentwurf oder die andere Vorlage hierzu in überarbeiteter Form einreichen. ${ }^{6}$ Der Senat führt das Volksbegehren durch. ${ }^{7}$ Die Volksinitiatoren sind berechtigt, Unterschriften auf eigenen Listen zu sammeln. ${ }^{8}$ Das Volksbegehren ist zustande gekommen, wenn es von mindestens einem Zwanzigstel der Wahlberechtigten unterstützt wird.

(3) ${ }^{1}$ Die Bürgerschaft befasst sich mit dem Anliegen des Volksbegehrens. ${ }^{2}$ Die Volksinitiatoren erhalten Gelegenheit, das Anliegen in einem Ausschuss zu erläutern. ${ }^{3}$ Sofern die Bürgerschaft nicht innerhalb von vier Monaten nach Einreichung der Unterschriften das vom Volksbegehren eingebrachte Gesetz verabschiedet oder einen Beschluss gefasst hat, der der anderen Vorlage vollständig entspricht, können die Volksinitiatoren die Durchführung eines Volksentscheides beantragen. ${ }^{4}$ Sie können den Gesetzentwurf oder die andere Vorlage hierzu in überarbeiteter Form einreichen. ${ }^{5}$ Der Senat legt den Gesetzentwurf oder die andere Vorlage dem Volk zur Entscheidung vor. ${ }^{6}$ Die Bürgerschaft kann einen eigenen Gesetzentwurf oder eine eigene andere Vorlage beifügen. ${ }^{7}$ Der Volksentscheid findet am Tag der Wahl zur Bürgerschaft oder zum Deutschen Bundestag statt. ${ }^{8}$ Auf Antrag der Volksinitiative kann der Volksentscheid über einfache Gesetze und andere Vorlagen auch an einem anderen Tag stattfinden. ${ }^{9}$ Dasselbe gilt, wenn die Bürgerschaft dies im Falle eines Volksentscheides nach Absatz 4 oder 4 a beantragt. 10Findet der Volksentscheid am Tag der Wahl zur Bürgerschaft oder zum Deutschen Bundestag statt, so ist ein Gesetzentwurf oder

44 Koalitionsvertrag vom 17.4.2008, S. 59, Internetquelle: http://www.cduhamburg.de/27002/ Uploaded/2008_koalitionsvertrag.pdf (Aufruf am 8.9.2009).

45 Gesetz v. 16.12.2008, HmbGVBl. 2008, S. 431. 
eine andere Vorlage angenommen, wenn die Mehrheit der Abstimmenden zustimmt und auf den Gesetzentwurf oder die andere Vorlage mindestens die Zahl von Stimmen entfällt, die der Mehrheit der in dem gleichzeitig gewählten Parlament repräsentierten Hamburger Stimmen entspricht. ${ }^{11}$ Verfassungsänderungen bedürfen einer Mehrheit von zwei Dritteln der Abstimmenden und mindestens zwei Dritteln der in dem gleichzeitig gewählten Parlament repräsentierten Hamburger Stimmen. ${ }^{12}$ Steht den Wahlberechtigten nach dem jeweils geltenden Wahlrecht mehr als eine Stimme zu, so ist für die Ermittlung der Zahl der im Parlament repräsentierten Hamburger Stimmen nach den Sätzen 10 und 11 die tatsächliche Stimmenzahl so umzurechnen, dass jeder Wahlberechtigten und jedem Wahlberechtigten nur eine Stimme entspricht. 13Findet der Volksentscheid nicht am Tag der Wahl zur Bürgerschaft oder zum Deutschen Bundestag statt, so ist er angenommen, wenn die Mehrheit der Abstimmenden und mindestens ein Fünftel der Wahlberechtigten zustimmt.

(4) ${ }^{1}$ Ein von der Bürgerschaft beschlossenes Gesetz, durch das ein vom Volk beschlossenes Gesetz aufgehoben oder geändert wird (Änderungsgesetz), tritt nicht vor Ablauf von drei Monaten nach seiner Verkündung in Kraft. ${ }^{2}$ Innerhalb dieser Frist können zweieinhalb vom Hundert der Wahlberechtigten einen Volksentscheid über das Änderungsgesetz verlangen. ${ }^{3}$ In diesem Fall tritt das Änderungsgesetz nicht vor Durchführung des Volksentscheids in Kraft. ${ }^{4}$ Das Volk entscheidet über das Änderungsgesetz. ${ }^{5}$ Absatz 3 Sätze 5, 7 und 10 bis 13 ist sinngemäß anzuwenden.

(4 a) ${ }^{1}$ Ein Volksentscheid über eine andere Vorlage bindet Bürgerschaft und Senat. ${ }^{2}$ Die Bindung kann durch einen Beschluss der Bürgerschaft beseitigt werden. ${ }^{3}$ Der Beschluss ist im Hamburgischen Gesetz- und Verordnungsblatt zu verkünden. ${ }^{4} \mathrm{Er}$ wird nicht vor Ablauf von drei Monaten nach seiner Verkündung wirksam. ${ }^{5}$ Absatz 4 Sätze 2 bis 5 ist sinngemäß anzuwenden.

(5) Während eines Zeitraumes von drei Monaten vor dem Tag einer allgemeinen Wahl in Hamburg finden keine Volksbegehren und Volksentscheide statt.

(6) 'Das Hamburgische Verfassungsgericht entscheidet auf Antrag des Senats, der Bürgerschaft, eines Fünftels der Abgeordneten der Bürgerschaft oder der Volksinitiatoren über die Durchführung von Volksbegehren und Volksentscheid. ${ }^{2}$ Volksbegehren und Volksentscheid ruhen während des Verfahrens.

(7) ${ }^{1}$ Das Gesetz bestimmt das Nähere. ${ }^{2}$ Es kann auch Zeiträume bestimmen, in denen die Fristen nach Absatz 2 Satz 4 und Absatz 3 Satz 3 wegen sitzungsfreier Zeiten der Bürgerschaft oder eines von der Bürgerschaft auf Vorschlag der Volksinitiatoren gefassten Beschlusses nicht laufen.

Konnte über die Volksgesetzgebung Einigkeit erzielt werde, bestand doch ein Dissens zwischen den Koalitionspartnern hinsichtlich des Wahlrechts. Im Koalitionsvertrag stellten die Koalitionäre die Meinungsverschiedenheit fest und verwiesen auf einen möglichen Volksentscheid. Die GAL verpflichtete sich, ,durch ihr Abstimmungsverhalten der CDU [zu] ermöglichen, zu dem Vorschlag der Volksinitia- 
tive dem Volk einen Gegenvorschlag der Bürgerschaft vorzulegen“. ${ }^{46}$ Tatsächlich war bereits eine weitere Initiative angelaufen (,Mehr Demokratie - Ein faires Wahlrecht für Hamburg"), die am Tag der Bundestagswahl am 27. September 2009 zum Volksentscheid anstehen sollte. Zu dieser Nagelprobe kam es indes nicht: Nach der erfolgreichen Durchführung des Volksbegehrens im Januar und Februar 2009 übernahm die Bürgerschaft die Vorschläge der Volksinitiative am 8. Juli 2009 durch eine neuerliche Verfassungsänderung. ${ }^{47}$ Der Volksentscheid wurde daraufhin abgesetzt. ${ }^{48}$ Die Änderung betraf im Kern eine Neufassung der Wahlgesetzgebung. Art. 6 Abs. $4 \mathrm{HmbV}$ lautet jetzt:

${ }^{1}$ Das Gesetz bestimmt das Nähere. ${ }^{2}$ Gesetzesbeschlüsse der Bürgerschaft bedürfen einer Mehrheit von zwei Dritteln der abgegebenen Stimmen. ${ }^{3}$ Auf die so beschlossenen Gesetze ist Artikel 50 Absatz 4 Sätze 1 bis 4 und Absatz 3 Sätze 5, 7, 9, 11 und 12 mit der Maßgabe anzuwenden, dass das Gesetz im Fall des Satzes 9 einer Mehrheit von zwei Dritteln der Abstimmenden und der Zustimmung von mindestens einem Fünftel der Wahlberechtigten bedarf. ${ }^{4}$ Fü durch Volksbegehren eingebrachte Gesetzesvorlagen gilt Artikel 50 Absatz 3 Satz 11 entsprechend; Artikel 50 Absatz 3 Satz 8 ist nicht anzuwenden.

Durch Einfügung eines Satzes 3 in Art. 4 Abs. $2 \mathrm{HmbV}$ wurden Sätze 2-4 von Art. 6 Abs. 4 auf die Wahl zu den Bezirksversammlungen für entsprechend anwendbar erklärt.

\section{Die Entwicklung im Rückblick}

Blickt man auf die Entwicklung, namentlich auf die Konflikte zwischen 2004 und 2008 zurück, werden einige zentrale Streitpunkte erkennbar, die ihren Niederschlag in den jüngsten Verfassungs- und Gesetzesänderungen gefunden haben: In verfahrensbezogener Hinsicht stellte sich stets die Frage nach einer Mobilisierung der Abstimmenden. Der Streit um Art und Höhe der Quoren, um die Abstimmungstage und den Modus der Unterschriftensammlungen drehte sich letztlich darum, Mobilisierungsschwächen zu überwinden oder aber auszunutzen. Die größten Erfolge konnten die Initiatoren immer dann verbuchen, wenn der Volksentscheid mit einer Parlamentswahl gekoppelt war; umgekehrt hatte sich die Hürde für Verfassungsänderungen auch bei Zusammenlegung mit Wahlen als prohibitiv erwiesen.

Der zweite große Streitpunkt betraf die Verbindlichkeit von Volksentscheiden. Hier hatte das Hamburgische Verfassungsgericht mit seiner Rechtsprechung die „anderen Vorlagen“ in den Bereich weitgehend unverbindlicher Stimmungsbilder abgeschoben und durch seine zurückhaltende Handhabung des Grundsatzes der Organtreue der parlamentarischen Konterlegislatur wenig Grenzen gesetzt. Umso mehr

46 Koalitionsvertrag (Fn. 44), S. 59.

47 HmbGVB1. 2009, S. 221.

48 Hamburgische Bürgerschaft, Drs. 19/3648 v. 21.7.2009. 
musste es den plebiszitär Bewegten innerhalb und außerhalb des Vereins „Mehr Demokratie" angelegen sein, hier Verbindlichkeit zu schaffen.

Bemerkenswert an der Entwicklung in Hamburg ist, dass Forderungen der Volksinitiativen trotz Scheiterns an den Abstimmungsquoren oder durch parlamentarische Korrektur von der Bürgerschaft im Nachhinein übernommen wurden. ${ }^{49}$ Hierfür dürften klare Mehrheiten für die gescheiterten Entwürfe ebenso verantwortlich $\operatorname{sein}^{50}$ wie der Druck immer neuer Volksinitiativen, die sich nach einer Abstimmungsniederlage sogleich erneut formierten. Die überraschende Rücknahme der verschärften Regeln des HmbVAbstG durch Senat und Bürgerschaft mag zudem taktische Gründe gehabt haben: Die Erfüllung dieses Teils der Forderungen verringerte die Chancen für den zweiten, auf Änderung von Art. $50 \mathrm{HmbV}$ gerichteten Antrag. ${ }^{51}$ Auch der Eintritt der GAL in den Senat dürfte schließlich für die Auflösung der jüngsten Blockaden mitursächlich sein. Vielleicht aber kann man hinter dieser spezifisch hamburgischen Variante der „Refolution“52 auch einen ,großen gesellschaftlichen Lernprozess“ sehen, der von der „Responsivität des repräsentativ-demokratischen Systems“" zeugt. ${ }^{53}$

II. Die Verfassungsänderungen vom Dezember 2008 und Juli 2009

\section{Sachliche Reichweite des Plebiszits}

\section{a) Allgemeines}

Art. 50 Abs. 1 S. 1 HmbV n.F. definiert erstmals die ,,anderen Vorlagen“, von denen in den folgenden Absätzen die Rede ist (,Befassung mit bestimmten Gegenständen der politischen Willensbildung"). Der Legaldefinition dürfte primär klarstellende Funktion zukommen. Auch mit der Streichung des Zusatzes, wonach Anträge sich „im Rahmen der Zuständigkeit der Bürgerschaft“ zu bewegen haben, sind, der Begründung zufolge, keine sachlichen Änderungen bezweckt; ebenso soll die Aufnahme der Bundesratsinitiativen in den Ausschlusskatalog nur „Rechtsklarheit hin-

49 Hiermit steht Hamburg jedoch nicht allein: Für einen ähnlichen Fall in Thüringen spricht Tobias Franke-Polz, Direkte Demokratie in Thüringen, in: Kost, Direkte Demokratie (Fn. 3), S. 294-311 (300) davon, das Volksbegehren sei „quasi ,erfolgreich gescheitert““. Nach Silvano Möckli, Direkte Demokratie: Ein Vergleich der Einrichtungen und Verfahren in der Schweiz und Kalifornien, unter Berücksichtigung von Frankreich, Italien, Dänemark, Irland, Österreich, Liechtenstein und Australien, 1994, S. 283 f. (in Anlehnung an Juan Felix Gut), ist dieses auch als „Nachwirkung“ bekannte Phänomen zu den „primär-indirekten Wirkungen“ von Volksentscheiden zu rechnen.

50 Fraude, Hamburg (Fn. 3), S. 121 f.; Decker, Demokratie (Fn. 2), S. 121 f.; Rux, Demokratie (Fn. 2), S. $799 \mathrm{f}$.

51 Rux, Demokratie (Fn. 2), S. 843 f.

$52 \mathrm{Zu}$ diesem Konzept Timothy Garton Ash, Refolution, in: ders., The Uses of Adversity: Essays on the Fate of Central Europe, 1989, S. 309-324.

53 So die Deutung von Jung, Konterlegislatur (Fn. 31), S. 440. 
sichtlich der Beschränkung auf Gegenstände des Landesrechts“ s schaffen. ${ }^{54}$ Während unstrittig ist, dass auch der Volksgesetzgeber auf Landesebene die Verbandskompetenz des Landes zu achten hat, ${ }^{55}$ stellt die Neufassung im Zusammenspiel mit der Legaldefinition der „anderen Vorlage“ jedoch zugleich klar, dass Anträge nicht an die Organkompetenz der Bürgerschaft gekoppelt sind, sondern auch in den Kompetenzbereich des Senats fallen können. Art. $50 \mathrm{Abs} .1 \mathrm{~S} .1$ und $2 \mathrm{HmbV}$ bestimmen die sachliche Reichweite der Plebiszite lediglich für die Stufe der Volksinitiative. Da diese jedoch dem dreistufigen Modell der Volksgesetzgebung entsprechend die Vorstufe für Volksbegehren und Volksgesetzgebung ist, erstrecken sich die Regelungen auch auf die nachfolgenden Verfahrensstufen. ${ }^{56}$

\section{b) Haushaltsvorbehalt}

Der Haushaltsvorbehalt ist ein klassischer Zankapfel der Volksgesetzgebung. ${ }^{57}$ Das Hamburgische Verfassungsgericht war vor allem im Zusammenhang mit der Initiative „VolXUni - Rettet die Bildung!“ mit der Auslegung des Vorbehaltes in Art. 50 Abs. $1 \mathrm{HmbV}$ a.F. befasst. Es hatte sich hier einer verbreiteten Sicht $^{58}$ angeschlossen, wonach ein solcher Vorbehalt nicht nur das Haushaltsgesetz als solches, sondern prinzipiell alle finanzwirksamen Vorlagen erfasse, sofern sie, in einer „wertenden Gesamtbetrachtung“, „wesentliche“ Auswirkungen auf den Landeshaushalt haben. ${ }^{59}$ Erleichtert wurde diese Lesart durch den Begriff der „Haushaltsangelegenheiten“ in der bisherigen Fassung. So verwies das Gericht zur Stützung seiner Interpretation ausdrücklich darauf, dass der Verfassunggeber nicht den Begriff des „Haushaltsgesetzes“ oder des „Haushaltsplans“ gewählt habe. ${ }^{60}$

54 Hamburgische Bürgerschaft, Drs. 19/1476, S. 3.

55 Peter Krause, Verfassungsrechtliche Möglichkeiten direkter Demokratie, in: Josef Isensee/ Paul Kirchhof (Hrsg.), Handbuch des Staatsrechts der Bundesrepublik Deutschland, Bd. 3, 3. Aufl. 2005, §35 Rn. 28; Bernd J. Hartmann, Volksgesetzgebung in Ländern und Kommunen, DVB1. 2001, 776-785 (778). Vgl. auch Josef Isensee, Verfahrensfragen der Volksgesetzgebung - Überlegungen zum Landesverfassungsrecht, in: FS für Peter Krause, 2006, S. 303-323 (311).

56 Josef Isensee, Plebiszit unter Finanzvorbehalt, in: FS für Reinhard Mußgnug, 2005, S. 101-127 (116): „Was von Anfang an unzulässig ist, kann im weiteren Lauf des Verfahrens nicht zulässig werden." Insoweit übereinstimmend auch Julia Platter, Neue Entwicklungen in der Rechtsprechung zum Haushaltsvorbehalt bei der Volksgesetzgebung, ZParl 35 (2004), S. 496-512 (510 f.).

57 Vertiefend dazu mit umfassenden Nachweisen Neumann, Demokratie (Fn. 2), Rn. 806-955.

58 BayVerfGH, Entsch. v. 17.11.1994, Vf. 96-IX-94 u.a., DVB1. 1995, S. 419-427 (425 f.); StGH Bremen, Entsch. v. 17.6.1997, St 7/96, NVwZ 1998, S. 388-391 (389 f.); BVerfGE 102, 176 (185-189); ThürVfGH, Urt. v. 19.9.2001, LKV 2002, S. 83-97 (91-93); BbgVerfG, Urt. v. 20.9.2001, VfGBbg 57/00, LKV 2002, S. 77-83.

59 HmbVerfG, Urt. v. 22.4.2005, HVerfG 5/04 (VolXUni I), DVBl. 2006, S. 631-647 (635 f.). Dazu Rux, Demokratie (Fn. 2), S. 805 f.

60 HmbVerfG, a.a.O., S. 633, 635 f. 
Dass nunmehr nur noch Initiativen zum „Haushaltsplan“ ausgeschlossen sein sollen, könnte, gerade auch im systematischen Zusammenhang mit der ausdrücklichen Nennung auch der wichtigsten finanzwirksamen Gesetze jenseits des Haushaltsgesetzes ${ }^{61}$ (Abgaben, Tarife der öffentlichen Unternehmen, Dienst- und Versorgungsbezüge), signalisieren, dass der Haushaltsvorbehalt auf das formelle Haushaltsgesetz zurückgeführt werden sollte. Die Initiatoren hatten diese Änderung gefordert, um klarzustellen, „dass nur direkte Eingriffe in den Haushaltsplan ausgenommen sind“.62 Im Entwurf der Bürgerschaft hingegen heißt es nur noch, „dass finanzwirksame Vorlagen grundsätzlich zulässig sind (vergleiche HVerfG 5/04)“. ${ }^{63}$ Die Umformulierung und der ,vergleichende“ Hinweis auf die bisherige Rechtsprechung des Hamburgischen Verfassungsgerichts deuten auf eine Beibehaltung des Status quo hin.

Abweichend von dem Entwurf der Volksinitiative gibt Art. 50 Abs. 2 S. 2 HmbV n.F. der Bürgerschaft bzw. einem Fünftel ihrer Mitglieder das Recht, eine Prüfung durch den Rechnungshof zu veranlassen. Die Stellungnahme des Rechnungshofes (zu der dieser nicht verpflichtet ist ${ }^{64}$ ) könnte dem Verfassungsgericht in Zukunft die Entscheidung darüber erleichtern, ob eine wesentliche Beeinträchtigung des Landeshaushalts droht. Denn dass das Hamburgische Verfassungsgericht seine bisherige Rechtsprechung zum Haushaltsvorbehalt grundlegend ändert, steht angesichts der unklaren Signale in der Gesetzesbegründung nicht zu erwarten. ${ }^{65}$ Hinzu kommt, dass die Rechtsprechung der Landesverfassungsgerichte allen Textvarianten zum Trotz, von erstaunlicher Homogenität geprägt ist. ${ }^{66}$ Ob von „Haushaltsgesetz“, „Haushaltsplan“ oder „Haushaltsangelegenheiten“ die Rede ist, spielt danach im Ergebnis kaum eine Rolle. Der Ursprung dieser vereinheitlichenden Lesart dürfte im Rekurs auf Art. 73 Abs. 4 WRV liegen, der überwiegend materiell und eher weit verstanden wurde $^{67}$ - übrigens trotz (?) der Verwendung des Wortes „Haushaltsplan“, für den sich nun der verfassungsändernde Gesetzgeber in Hamburg entschieden hat. Allenfalls könnte (und sollte) sich das Hamburgische Verfassungsgericht durch die Textänderung veranlasst sehen, bei der Bestimmung, wann eine Beeinträchtigung des

$61 \mathrm{Zu}$ diesem systematischen Argument Johannes Rux, Die Haushaltsvorbehalte in Bezug auf die direktdemokratischen Verfahren in den Verfassungen der neuen Bundesländer, LKV 2002, S. 252-257 (253 f.).

62 Hamburgische Bürgerschaft, Drs. 18/8068, S. 4.

63 Hamburgische Bürgerschaft, Drs. 19/1476, S. 3.

64 Hamburgische Bürgerschaft, Drs. 19/1476, S. 3.

65 Neben dem Wortlaut hat das Gericht zur Begründung auch auf die Intention des Verfassunggebers abgestellt: HmbVerfG, HVerfG 5/04 (VolXUni I) (Fn. 59), DVBl. 2006, S. 635 f.

66 Kritisch und m.w.N. Fabian Wittreck, Direkte Demokratie und Verfassungsgerichtsbarkeit, JöR 53 (2005), S. 111-185 (116, 178-181). Zustimmend dagegen Peter Selmer, Gestaltung der Finanz- und Wirtschaftsrechtsordnung durch Volksentscheid?, in: FS für Rolf Stober, 2008, S. 179-194 (187). Eingehend zur Bestimmung des Inhalts der allgemeinen Haushaltsvorbehalte Jürgen Krafczyk, Der parlamentarische Finanzvorbehalt bei der Volksgesetzgebung, 2005, S. 68-221.

67 Dazu u.a. StGH Bremen (Fn. 58), S. 389; BVerfGE 102, 176 (185); BbgVerfG (Fn. 58), S. 78; HmbVerfG (Fn. 59), S. 633. Vertiefend Otmar Jung, Das Finanztabu bei der Volksgesetzgebung. Die Staatsrechtslehre und Staatspraxis der Weimarer Zeit, Der Staat 38 (1999), S. 41-68. 
Haushalts als ,wesentlich“ anzusehen ist, etwas strengere Maßstäbe anzulegen als Verfassungsgerichte mancher anderer Bundesländer. ${ }^{68}$

\section{Verfahrensfragen}

\section{a) Behandlung der Vorlagen in der Bürgerschaft}

\section{aa) Befassungspflicht und Erläuterungsrecht}

Neu aufgenommen wurde in Abs. 2 und 3 eine Pflicht der Bürgerschaft, sich mit dem Antrag der Volksinitiative bzw. mit dem Volksbegehren zu befassen. Flankiert wird diese Pflicht durch das ebenfalls neu verbriefte Recht der Volksinitiatoren, ihr Anliegen in einem (sinngemäß zu ergänzen ist: zuständigen) Bürgerschaftsausschuss zu erläutern. Diese Regelung ,,verfolgt den Zweck, die Stellung der Volksinitiatoren zu stärken und einen Austausch zwischen Bürgerschaft und Initiatoren mit dem Ziel der Suche nach einer gemeinsamen Lösung herbeizuführen"69. Damit stellt sich die Frage nach dem Verhältnis von Volksinitiative und Volkspetition umso nachdrücklicher. War es bisher in Hamburg so, dass - abweichend von der gängigen Typologie $^{70}$ - die Volkspetition mit Befassungspflicht und Erläuterungsrecht verbunden war, nicht dagegen die Volksinitiative, sind beide nunmehr an die gleichen Voraussetzungen geknüpft (10.000 Unterschriften) und verpflichten beide die Bürgerschaft, mit den Trägern der Initiative bzw. der Petition ins Gespräch zu treten. Dass die Bürgerschaft sich schon zuvor in der Praxis mit Volksinitiativen (und -begehren) befasst hat, steht auf einem anderen Blatt. ${ }^{71}$ Der entscheidende Unterschied zwischen Volkspetition und Volksinitiative, der den Fortbestand der Sammelpetition rechtfertigt, ist, dass nur die Volksinitiative, nicht aber die Volkspetition, als erste Stufe zur Gesetzgebung den sachlichen Grenzen des Art. 50 Abs. $1 \mathrm{HmbV}$ unterliegt. In einer Volkspetition können daher auch Anliegen vorgetragen werden, die im Realisierungsfall wesentliche Auswirkungen auf den Landeshaushalt hätten. ${ }^{72}$

\section{bb) Vollständige Übernahme der Vorlage durch die Bürgerschaft}

Wie bisher auch, kann die Bürgerschaft das Volksbegehren bzw. den Volksentscheid abwenden, indem sie die Vorlage übernimmt. Die frühere Fassung bestimmte dabei, dass das Gesetz der Bürgerschaft der Vorlage ,entsprechen“ müsse. Die Neu-

68 Zur verfassungsrechtlichen Würdigung noch unten III.2.a.

69 Hamburgische Bürgerschaft, Drs. 19/1476, S. 3.

70 Rux, Demokratie (Fn. 2), S. 802, 804 f.; Neumann, Demokratie (Fn. 2), Rn. 281-283.

71 Aus diesem Grunde zweifelte Rux, Demokratie (Fn. 2), S. 846 schon auf Grundlage der früheren Fassung des Art. $50 \mathrm{HmbV}$ am verfassungspolitischen Sinn der Volkspetition neben der Volksinitiative.

72 Vgl. zur Volksinitiative in einem zweistufigen Modell der Volksgesetzgebung Dieter Birk/ Rainer Wernsmann, Volksgesetzgebung über Finanzen, DVB1. 2000, S. 669-675 (675). 
fassung sieht nunmehr vor, dass das Parlamentsgesetz der Vorlage „,vollständig“ zu entsprechen hat, weswegen nur redaktionelle, nicht aber inhaltliche Änderungen den Antrag gegenstandslos machen. ${ }^{73}$ Die Feststellung obliegt nach $\S \S 6$ Abs. 1 S. 2, 18 Abs. 1 S. 2 HmbVAbstG der Bürgerschaft (die aber schon nach der alten Verfassungslage keine Einschätzungsprärogative besa ${ }^{74}$ ); die Initiatoren können gegen diese Feststellung beim Verfassungsgericht klagen (§ 27 Abs. 1 S. 1 Nr. 2 HmbVAbstG). Die Frist zur Übernahme beträgt drei Monate bei einer Volksinitiative und wurde für die Übernahme eines Volksbegehrens auf vier Monate verlängert. Hintergrund ist eine Angleichung an das HmbVAbstG und die Sorge um eine faktische Fristverkürzung durch die Aufnahme eines Zeitpunkts, ab dem die Frist zu laufen beginnt, in den Verfassungstext. ${ }^{75}$ Alternativ zur Übernahme steht es der Bürgerschaft nach wie vor frei, eine Konkurrenzvorlage für den Volksentscheid zur Abstimmung zu stellen (Art. 50 Abs. 3 S. 6 HmbV).

\section{cc) Handlungsoptionen der Volksinitiatoren}

Der Sinn der Übernahmefristen in Abs. 2 und 3 ist es, Luft für Einigungsversuche zwischen Bürgerschaft und Volksinitiatoren zu schaffen. Hierzu wurde seinerzeit auch ausdrücklich das Recht der Initiatoren aufgenommen, die Vorlage zurückzunehmen. ${ }^{76}$ Dass dieses Recht in der Neufassung gestrichen ist, ist ohne Bedeutung. Dass die Initiatoren die Durchführung von Volksbegehren bzw. Volksentscheid beantragen „können“, impliziert bereits ein Recht zur Rücknahme, ${ }^{77}$ wie es $\S 8 \mathrm{HmbV}$ AbstG nach wie vor explizit vorsieht. Kommt es zu keiner Einigung mit der Bürgerschaft, können die Initiatoren das Verfahren weiter betreiben.

Für den Fall, dass sich durch Änderung der Sach- oder Rechtslage während oder in Folge der Verhandlungen mit der Bürgerschaft der Gegenstand der Vorlage verändert haben sollte, gestatten Art. 50 Abs. 2 S. 5 und Abs. 3 S. 4 die Einreichung der Vorlage in überarbeiteter Form. Hierdurch soll zugleich ermöglicht werden, Widersprüche und Unklarheiten auszuräumen. Nicht verändert werden dürfen indes „,[d]er Grundcharakter und die nach allgemeinem Verständnis angestrebten Ziele oder Teilziele der Volksinitiative“". ${ }^{78}$ Ob der neugefasste Entwurf die Grenzen der Überarbeitung wahrt, können der Senat, die Bürgerschaft oder ein Fünftel der Bürgerschaftsabgeordneten nach $\S 26$ Abs. 1 Nr. 2 HmbVAbstG verfassungsgerichtlich überprüfen lassen. Auf die problematischen Aspekte dieses Überarbeitungsrechts wird an anderer Stelle noch einzugehen sein (unten III.2.b); dass es nunmehr in der

73 Hamburgische Bürgerschaft, Drs. 19/1476, S. 3.

74 HmbVerfG, Urt. v. 30.11.2005, HVerfG 16/04, DVBl. 2006, S. 650 f. (nur LS); Rux, Demokratie (Fn. 2), S. 816.

75 Hamburgische Bürgerschaft, Drs. 19/1476, S. 4.

76 Stüber, Volksabstimmungen (Fn. 24), S. 228, 231. Eingehend zur Diskussion über ein speziell zu regelndes Einigungsverfahren Thies Bösling, Das Besondere Einigungsverfahren zwischen Hamburgischer Bürgerschaft und Initiatoren im Volksgesetzgebungsverfahren, 2002.

77 Hamburgische Bürgerschaft, Drs. 19/1476, S. 3, 4.

78 Hamburgische Bürgerschaft, Drs. 19/1476, S. 4. 
Verfassung selbst garantiert wird, lässt aber immerhin Bedenken gegen $\S 6$ Abs. 3 bzw. $§ 18$ Abs. 3 HmbVAbstG entfallen, die ein Überarbeitungsrecht schon zuvor ohne verfassungsrechtliche Grundlage vorsahen. ${ }^{79}$ Unbefriedigend erscheint hingegen die in $\S 18$ Abs. $3 \mathrm{~S}$. 1 HmbVAbstG vorgesehene Frist von einem Monat nach Feststellung des Zustandekommens des Volksbegehrens. ${ }^{80}$ Soll mit der Überarbeitung gerade auf Veränderungen im Laufe des Einigungsprozesses reagiert werden, scheint eine Synchronisierung mit der Frist geboten, die der Bürgerschaft zur Übernahme der Vorlage zur Verfügung steht. Das Überarbeitungsrecht knüpft in Art. 50 Abs. $3 \mathrm{~S} .4 \mathrm{HmbV}$ an die fehlende Übernahme durch die Bürgerschaft innerhalb einer Frist von vier Monaten nach Einreichung der Unterschriften an und koppelt die Vorlage der überarbeiteten Fassung an den Volksentscheid (,hierzu“). Die Ein-Monats-Frist ist somit weder nach Wortlaut noch nach Systematik oder Sinn und Zweck mit Art. 50 Abs. $3 \mathrm{HmbV}$ vereinbar.

\section{dd) Rechtliche Überprüfbarkeit der Vorlage?}

Die Frage der Überarbeitung hat auch Konsequenzen für die rechtliche Überprüfbarkeit der Vorlage. Da die Volksinitiative schon die erste Stufe der Volksgesetzgebung bildet, kennt das Hamburger Recht kein gesondertes Zulassungsverfahren, in dem die Vereinbarkeit einer Vorlage mit höherrangigem Recht überprüft werden könnte. ${ }^{81}$ Nun steht außer Frage, dass auch der Volksgesetzgeber die Landesverfassung, das einschlägige Bundesrecht und das Europäische Gemeinschaftsrecht achten muss: Er ist als von der Verfassung ermächtigtes Organ selbst pouvoir constitué und somit rechtsgebunden. ${ }^{82}$ Ebenso dürfte der allgemeinen Rechts- und Verfassungsbindung wegen eine Kontrollpflicht von Senat und Bürgerschaft anzunehmen sein, obgleich $\S 5$ Abs. 2 bzw. $§ 16$ Abs. 1 HmbVAbstG nur bestimmen, dass der Senat die formalen Voraussetzungen der Abstimmung zu prüfen hat. ${ }^{83}$ Senat oder Bürgerschaft dürfen eine Vorlage aber nicht eigenmächtig anhalten; vielmehr können sie (sowie ein Fünftel der Bürgerschaftsabgeordneten) gemäß Art. 50 Abs. 6 (siehe außerdem Art. 65 Abs. 3 Nr. 5) HmbV i.V.m. § 26 Abs. 1 Nr. 1 HmbVAbstG das Verfassungsgericht ,über die Durchführung des Volksbegehrens“, und d.h. auch: über die materielle Rechtmäßigkeit der Vorlage entscheiden lassen. Die Überprüfung bezieht sich jedenfalls auf die Einhaltung der sachlichen Grenzen der Volks-

79 Dazu Rux, Demokratie (Fn. 2), S. 811 f., 816, der die $\S \S 6$ Abs. 3, 18 Abs. 3 HmbVAbstG für nichtig hielt. Die Annahme einer Nichtigkeit ex tunc zumindest hätte streng genommen zur Folge, dass die Vorschriften ohne erneuten Beschluss auch nicht durch Änderung der verfassungsrechtlichen Voraussetzungen geheilt werden könnten.

80 Von einem Redaktionsversehen geht insoweit Rux, Demokratie (Fn. 2), S. 817 aus.

81 v. Arnim, Schein (Fn. 6), S. 215; Weixner, Demokratie 2002 (Fn. 23), S. 107 f.; dies., Demokratie 2006 (Fn. 23), S. 19.

82 Isensee, Verfahrensfragen (Fn. 55), S. 311; Rux, Demokratie (Fn. 2), S. 87-90. Eingehend zur Grundrechtsbindung Bernd J. Hartmann, Volksgesetzgebung und Grundrechte, 2005, S. 98-112, passim.

83 Allgemein Isensee, Verfahrensfragen (Fn. 55), S. 313-318. 
gesetzgebung aus Art. $50 \mathrm{Abs} .1 \mathrm{HmbV},{ }^{84}$ bezieht aber - dem Gedanken der Einheit der Verfassung folgend - auch die Kontrolle am Maßstab des übrigen Landesverfassungsrechts ein. Dass ebenso das Bundesrecht den Maßstab einer „Normentwurfskontrolle“ bilden kann, ist nicht bloß verfassungspolitische Forderung, ${ }^{85}$ sondern lässt sich aus einer Interpretation von Art. $1 \mathrm{HmbV}$ („Die Freie und Hansestadt Hamburg ist ein Land der Bundesrepublik Deutschland") im Lichte von Art. 28 Abs. 1 und Art. $31 \mathrm{GG}$ auch verfassungsrechtlich stützen. ${ }^{86}$ Die Frage bleibt freilich weitgehend theoretisch: Schließlich wird ein Antrag auf präventive Normenkontrolle regelmäßig verfrüht sein, solange noch die Möglichkeit besteht, die rechtlichen Bedenken im Wege einer Überarbeitung des Entwurfs auszuräumen. ${ }^{87}$ Hier bleibt allein die Möglichkeit einer Normenkontrolle ex post (Art. 65 Abs. 3 Nr. 3 und 6 $\mathrm{HmbV}$ ). Dies wird indes nur Fälle betreffen, in denen die Rechtsfrage zwischen Bürgerschaft und Volksinitiatoren umstritten ist. Ansonsten werden jene schon im eigenen Interesse auf Hinweis aus der Bürgerschaft eine entsprechende Überarbeitung vornehmen.

\section{b) Mobilisierungsrelevante Verfahrensregeln}

Von zentraler Bedeutung für den Erfolg eines Plebiszits ist, welcher Grad an Beteiligung und Zustimmung gefordert ist und welche Rahmenbedingungen für eine Mobilisierung der Stimmbevölkerung existieren. Gerade das Verfahrensrecht hat hier eine entscheidende Steuerungswirkung. ${ }^{88}$ Die erforderlichen Quoren, die einzuhaltenden Fristen und die Abstimmungsmodalitäten stehen in einer Wechselwirkung zueinander. ${ }^{89}$ Wo in einem stark formalisierten Verfahren binnen kurzer Frist ein hohes Quorum zu überwinden ist, wird eine ausreichende Mobilisierung kaum je gelingen; umgekehrt reicht eine geringe Mobilisierung aus, wo niedrige Quoren mit einem weitgehend entformalisierten Verfahren und großzügig bemessenen Fristen

84 Vgl. HmbVerfG (Fn. 59), S. 631-637. Insoweit übereinstimmend auch Rux, Demokratie (Fn. 2), S. 301.

85 Vgl. aber, mit beachtlichen Gründen, Rux, Demokratie (Fn. 2), S. 295-303.

86 Im Ergebnis ebenso, aber mit z.T. abweichender Begründung, Otmar Jung, Verfahrensprobleme der Volksgesetzgebung, ZG 8 (1993), S. 314-337 (318, 324); ders., Aktuelle Probleme der direkten Demokratie in Deutschland, ZRP 2000, S. 440-447 (442); Stefan Przygode, Die deutsche Rechtsprechung zur unmittelbaren Demokratie, 1995, S. 81, 124-151; Hartmann, Volksgesetzgebung (Fn. 82), S. 161 f., 203.

87 Zu diesem Zusammenhang Rux, Demokratie (Fn. 2), S. 296 f., 302 f. Vgl. aus umgekehrter Perspektive auch Przygode, Rechtsprechung (Fn. 86), S. 121-124 (präventive Normenkontrolle möglich und zulässig, weil der Entwurf unverrückbar ist). Die Frage wird vom HmbVerfG (Fn. 59), S. 636, nur gestreift.

88 Vertiefend Jung, Verfahrensprobleme (Fn. 86), S. 314-337 (am Beispiel der gesetzlichen Ausgestaltung in Sachsen-Anhalt); ders., Grundsatzfragen (Fn. 14), S. 321-339; v. Arnim, Schein (Fn. 6), S. 241-249.

89 v. Arnim, Schein (Fn. 6), S. 218 f. Zur Kombination der „Mobilisierungskoeffizienten“ Frist und Quorum auch Jung, Grundsatzfragen (Fn. 14), S. 324-326. Tabellarische Übersicht im Ländervergleich bei Magin/Eder/Vatter, Demokratie (Fn. 14), S. 350. 
zusammentreffen. Auch Art und Umfang der Informationen, die den Stimmberechtigten im Vorfeld zur Verfügung gestellt werden, sind für die Mobilisierung relevant.

\section{aa) Eintragungsmodalitäten für das Volksbegehren}

Welches Eintragungsverfahren für das Volksbegehren angemessen ist, kann unterschiedlich beurteilt werden. Bei der freien Sammlung von Unterstützerstimmen können durch direkte Ansprache vor Ort am ehesten Mobilisierungsschwächen überwunden werden. Zugleich aber kann auf diese Weise ein Erwartungsdruck erzeugt werden, durch den sich der Angesprochene zu einer Eintragung gedrängt fühlt. ${ }^{90}$ Nicht auszuschließen ist ferner, dass der Unterzeichnende angesichts zahlreicher Unterschriftensammlungen keine genaue Vorstellung hat, wofür er sich einträgt. ${ }^{91}$ Umgekehrt kann die quasi-amtliche Auslegung von Eintragungslisten suggerieren, die Eintragung sei ,eine Art Bürgerpflicht“.92 Dass das Recht der Volksinitiatoren, Unterschriften auf eigenen Listen zu sammeln, nunmehr Aufnahme in die HmbV gefunden hat (Art. 50 Abs. 2 S. 7), erklärt sich aus den geschilderten Erfahrungen: Es soll verhindert werden, dass die Bürgerschaft erneut, wie schon 2005, durch Ausschluss der „freien“ Sammlung die Hürden für das Volksbegehren erhöht. Daneben bleiben auch weiterhin die Eintragung an öffentlichen Stellen (§ 9 Abs. 1 HmbVAbstG) und die Briefeintragung ( 13 HmbVAbstG) möglich. Insbesondere mittels einer Briefeintragung können Hemmschwellen gesenkt werden, ohne dass ein Abstimmungsdruck aufgebaut wird oder nicht genügend Möglichkeit zur Information über Inhalt und Hintergrund des Begehrens bleibt. Zwar ist der Zeitraum für die Durchführung des Volksbegehrens nach wie vor kurz (gemäß $§ 9$ Abs. 2 S. 1 HmbVAbstG drei Wochen). Die bessere Mobilisierungslage in einem dicht besiedelten Stadtstaat und die liberalen Eintragungsregeln vermögen dies jedoch zu kompensieren. ${ }^{93}$

\section{bb) Festlegung der Abstimmungstage}

Nachdem die Bürgerschaft 2005 versucht hatte, die Abstimmungstage von den Wahltagen zu lösen, und das Hamburgische Verfassungsgericht entschieden hatte, Art. 30 Abs. $5 \mathrm{HmbV}$ a.F. gebiete, dass eine Kopplung zumindest möglich sein müsse, ${ }^{94}$ schreibt Art. 50 Abs. 3 S. 7 HmbV jetzt vor, dass der Volksentscheid am Tag der Wahl zur Bürgerschaft oder zum Deutschen Bundestag stattzufinden hat. Damit sollen die Abstimmungen von der regelmäßig hohen Beteiligung an diesen Wah-

90 Hans Peter Bull, Direkte Demokratie in Hamburg - Chancen und Risiken, in: ders., Bürgerbeteiligung (Fn. 8), S. 16-37 (33).

91 Klaas Engelken, Kann ein Volksbegehren Sperrwirkung für Gesetzgebung und Regierung haben?, DVB1. 2005, S. 415-423 (421 f.).

92 Bull, Demokratie (Fn. 90), S. 34.

93 Rux, Demokratie (Fn. 2), S. 845, 895.

94 HmbVerfG (Fn. 40), S. 1590 f. Dazu oben I.2.b. 
len profitieren („Huckepack-Effekt“). ${ }^{95}$ Dass im Unterschied zum Entwurf der Initiatoren die Wahlen zum Europäischen Parlament nicht erwähnt sind, dürfte vor allem daran liegen, dass die Verfassung die Quoren jetzt mit dem Tag der Abstimmung verknüpft (dazu cc); zugleich wird auf diesem Wege aber auch eine Überfrachtung des Europawahltages vermieden, an dem nach dem Ergebnis des Volksentscheides vom 13. Juni 2004 künftig zugleich die Bezirksversammlungen gewählt werden sollen.

Die Volksinitiatoren können bei Abstimmungen über Gesetze und andere Vorlagen beantragen, dass der Volksentscheid auch an einem anderen Tag stattfindet (Art. 50 Abs. 3 S. 8). Dieses Antragsrecht ist vor den Erfahrungen mit dem Volksentscheid vom 14. Oktober 2007 zu interpretieren, bei dem die gezielte Entkopplung vom Tag der Bürgerschaftswahl einen gewichtigen Beitrag zum Scheitern der Abstimmung leistete. Daher wird man davon ausgehen müssen, dass der Senat dem Antrag zu entsprechen hat. Für Volksentscheide, die eine Verfassungsänderung zum Gegenstand haben, schreibt die Verfassung die Kopplung mit einem Wahltag verpflichtend vor, um für eine ausreichend breite Legitimationsbasis zu sorgen. ${ }^{96} \mathrm{Bei}$ Referenden über die Änderung volksbeschlossener Gesetze kann eine „Entkopplung" auch auf Antrag der Bürgerschaft erfolgen (Art. 50 Abs. 3 S. 9); hierauf wird im Zusammenhang mit der parlamentarischen Konterlegislatur zurückzukommen sein (unten 3.b, d). Für diese Fälle einer Abweichung auf Antrag (wie für die Terminierung von Volksbegehren) ist Art. $50 \mathrm{Abs}$. $5 \mathrm{HmbV}$ relevant, der unverändert bestimmt, dass während eines Zeitraumes von drei Monaten vor dem Tag einer allgemeinen Wahl keine Volksbegehren oder Volksentscheide stattfinden. Dies soll verhindern, dass Plebiszite im Wahlkampf instrumentalisiert werden, aber auch, dass sie Opfer eines Aufmerksamkeitsdefizits werden.$^{97}$ Irritierend ist, dass die Bürgerschaft keinen Anlass gesehen hat, § 18 Abs. 4 HmbVAbstG zu ändern. Dieser ist augenscheinlich noch an der alten Verfassungslage ausgerichtet. ${ }^{98}$

\section{cc) Quoren für den Volksentscheid}

Eine der markantesten Neuregelungen betrifft die Bestimmung zu den Quoren des Volksentscheides, die sich in den Sätzen 10 bis 13 von Art. 50 Abs. $3 \mathrm{HmbV}$ findet. In der komplexen Differenzierung spiegeln sich deutlich vergangene Debatten. Die

95 Hamburgische Bürgerschaft, Drs. 19/1476, S. 4. Zu diesem Effekt näher Otmar Jung, Das Quorenproblem beim Volksentscheid, ZfP 9 (1999), S. 863-898 (887-891), auch zu der gegenläufigen Gefahr, dass Anträge ,,auf die lange Bank“ geschoben werden; v. Arnim, Schein (Fn. 6), S. 228-231. Scharfe Kritik von Josef Isensee, Volksgesetzgebung - Vitalisierung oder Störung der parlamentarischen Demokratie?, DVB1. 2001, S. 1161-1170 (1169f.).

96 Hamburgische Bürgerschaft, Drs. 19/1476, S. 4.

97 Stüber, Volksabstimmungen (Fn. 24), S. 228.

$98 \S 18$ Abs. 4 HmbVAbstG lautet: „Der Senat führt den Volksentscheid vier Monate nach Antragstellung an dem folgenden Sonntag oder gesetzlichem (sic) Feiertag durch. Liegt dieser Termin in einem Zeitraum von drei Monaten vor oder einem Monat nach einer Wahl zur Bürgerschaft, zum Deutschen Bundestag oder zum Europäischen Parlament, so findet der Volksentscheid am Tag dieser Wahl statt.“ 
Grundidee hinter der Novelle liegt in einer Synchronisierung der Legitimationsniveaus direkter und repräsentativer Demokratie. Hinter einer Mehrheit bei einer Volksabstimmung sollen im Prinzip genauso viele Stimmberechtigte stehen wie hinter einer Mehrheit im Parlament Wahlberechtigte (Gedanke der Spiegelbildlichkeit). ${ }^{99}$ Das auf die Zahl der Stimmberechtigten bezogene starre Zustimmungsquorum, das hierzulande verbreitet ist, ${ }^{100}$ wird dazu weitgehend durch ein flexibles Quorum ersetzt. Dieses ,relationale“ Zustimmungsquorum orientiert sich an den bei Parlamentswahlen abgegebenen Stimmen. Damit reduziert sich der Mobilisierungsbedarf für die Volksgesetzgebung proportional zum Anteil der Nichtwähler bei allgemeinen Wahlen. Eine solche Kopplung kennt z.B. Art. 2 sect. 8 (b) und 9 (b) der Verfassung von Kalifornien, wonach für den Vorschlag zur Volksgesetzgebung oder für ein Referendum 5 \% (bei Verfassungsänderungen $8 \%$ ) derjenigen Stimmen nötig sind, die bei den letzten Gouverneurswahlen abgegeben wurden; für Bremen war eine vergleichbare Regelung im Gespräch, die aber am Staatsgerichtshof scheiterte. ${ }^{101}$ Das Hamburger Modell bezieht sich demgegenüber, und dies ist zumindest in Deutschland einmalig, nicht auf die Initiativphase, sondern auf den Volksentscheid.

Das zu erreichende Quorum wird nach Art. 50 Abs. 3 HmbV abhängig von den zeitgleich stattfindenden Wahlen zur Hamburgischen Bürgerschaft oder zum Deutschen Bundestag definiert - eine seltsam inkonsequente Mixtur aus naturalistischem und konstruktivistischem Verständnis von Repräsentation bzw. Repräsentativität. Der Kopplung als solcher liegt zunächst eine „naturalistische“ Interpretation der Repräsentation zugrunde, die schaut, wie viele Wählerstimmen „hinter“ einem Parlamentsabgeordneten stehen. Dies ist ein grundlegend anderer Ansatz als das traditionelle Repräsentationsverständnis, für das jeder Abgeordnete das gesamte Volk repräsentiert (vgl. Art. $7 \mathrm{HmbV}$ : „Die Abgeordneten sind Vertreterinnen und Vertreter des ganzen Volkes“). ${ }^{102}$ Von diesem anderen Ansatz aus wäre es konsequent, parlamentarischen Gesetzgeber und Volksgesetzgeber dadurch „,auf Augenhöhe“ zu

99 Vgl. Jung, Grundsatzfragen (Fn. 14), S. 324. Damit wird zugleich dem verbreiteten Vorwurf entgegengetreten, plebiszitäre Gesetzgebung führe im Gegensatz zur Parlamentsgesetzgebung zu Minderheitenherrschaft. Hiergegen näher Otmar Jung, Direkte Demokratie nach Schweizer Art in Deutschland verfassungswidrig?, KritV 84 (2001), S. 24-54 (32-39). Vgl. auch die Parallelisierung von Wahlen und Abstimmungen hinsichtlich des Erfordernisses einer Mindestbeteiligung bei Neumann, Demokratie (Fn. 2), Rn. 673-687 und hinsichtlich des Mehrheitsprinzips in Rn. 688-695.

100 Eingehend dazu und mit umfassenden Nachweisen Neumann, Demokratie (Fn. 2), Rn. 658-805. Siehe außerdem Jung, Quorenproblem (Fn. 95), S. 863-898. Guter Überblick über das Für und Wider bei Cornelius Thum, Zur Ausgestaltung des Mehrheitsprinzips in der unmittelbaren Demokratie, BayVB1. 2000, S. 33-43 und 74-79 (38-43).

101 BremStGH, Urt. v. 14.2.2000, St 1/98, DÖV 2000, S. 915-919 (917-919). Siehe auch Jung, Grundsatzfragen (Fn. 14), S. 312 (323 f.).

102 Näher zu diesem Repräsentationsverständnis Ernst-Wolfgang Böckenförde, Demokratie und Repräsentation, 1983, S. 18-28; ders., Demokratische Willensbildung und Repräsentation, in: Isensee/Kirchhof, Handbuch (Fn. 55), § 34 Rn. 26-29. Vgl. auch Hasso Hofmann, Parlamentarische Repräsentation in der parteienstaatlichen Demokratie, in: ders., Recht - Politik - Verfassung, 1986, S. 249-260. 
bringen, dass die bei der letzten (bzw. der zeitgleich stattfindenden) Bürgerschaftswahl abgegebenen Stimmen für maßgeblich erklärt werden. Volksgesetzgebung und Parlamentsgesetzgebung würden sich dann an demselben Prozentsatz von Aktivbürgern orientieren, der die Landespolitik de facto (d.h. in „naturalistischer“ Perspektive) legitimiert. Indem zusätzlich auf die Bundestagswahlen prozentuiert wird, ist dieser Zusammenhang jedoch durchbrochen. Es geht nicht mehr um eine Synchronisierung des Legitimationsniveaus der beiden konkurrierenden Landesgesetzgebungsorgane, sondern darum, eine Art „Mobilisierungskonnex“ zwischen dem Volksentscheid und der zeitgleich stattfindenden Wahl vorzunehmen. Das repräsentative Moment in dieser Legitimationsrechnung erscheint gleichsam virtuell und konstruiert. Wollte man nun aber dieses Modell konsequent durchführen, wären auch die Wahlen zum Europäischen Parlament einzubeziehen (so noch der Entwurf der Volksinitiative). Diese wurden jedoch wohlweislich wegen der regelmäßig niedrigen Wahlbeteiligung ausgeklammert. Die gewählte Lösung verfolgt also keinen Ansatz konsequent und gibt sich dadurch als Ergebnis eines mühsam errungenen Kompromisses zu erkennen.

Für den „Legitimationsvergleich“ werden nach Art. 50 Abs. 3 S. 10 und 11 $\mathrm{HmbV}$ die ,in dem gleichzeitig gewählten Parlament repräsentierten Hamburger Stimmen“ herangezogen. Zu berücksichtigen sind nur Stimmen, „die Einfluss auf die Sitzverteilung im Parlament haben“; ungültige Stimmen sind daher ebenso herauszurechnen wie Stimmen für Parteien, die an der nach derzeitigem Recht (dynamische Verweisung!) geltenden $5 \%$-Hürde scheitern. ${ }^{103}$ Maßgeblich sollen der Begründung zufolge bei Wahlen zum Deutschen Bundestag nur die Zweitstimmen sein. ${ }^{104}$ Dem wird man im Interesse der Praktikabilität folgen dürfen, auch wenn bei Überhangmandaten durchaus von einer Repräsentation Hamburger (Erst-)Stimmen im Bundestag die Rede sein könnte. Sieht das maßgebliche Wahlrecht, wie in Hamburg, die Möglichkeit von Stimmenhäufung (Kumulieren und Panaschieren) vor, so ist nach Art. 50 Abs. 3 S. $12 \mathrm{HmbV}$,die tatsächliche Stimmenzahl so umzurechnen, dass jeder Wahlberechtigten und jedem Wahlberechtigten nur eine Stimme entspricht“. Hier ergeben sich zweifelsohne neue rechnerische Herausforderungen für die Abstimmungsleitung.

Die zu erreichenden Quoren sind beim Volksentscheid künftig zum einen davon abhängig, ob eine Verfassungsänderung oder ein einfacher Gesetzesentwurf bzw. eine andere Vorlage zur Abstimmung steht, zum anderen, ob die Abstimmung am Tag einer Bürgerschafts- bzw. Bundestagswahl stattfindet oder an einem anderen Tag. Da über Verfassungsänderungen im Volksgesetzgebungsverfahren nur am Tag einer Bürgerschafts- oder Bundestagswahl abgestimmt werden darf (oben bb), ist die Regelung hier relativ einfach: Nach S. 11 ist eine Abstimmungsmehrheit von zwei Dritteln und eine im soeben beschriebenen Sinne „relationale“ Zustimmungsmehrheit von ebenfalls zwei Dritteln erforderlich. (Dass bei der Zustimmungsmehrheit, nicht dagegen bei der Abstimmungsmehrheit von „mindestens“ zwei Dritteln die Rede ist, bedeutet keinen Unterschied in der Sache, sondern ist einer unachtsa- 
men Schlussredaktion geschuldet.) Bei Volksentscheiden über einfache Gesetzesentwürfe oder andere Vorlagen kommt es für die Quoren auf den Tag der Abstimmung an. Ist dieser, wie in Art. 50 Abs. $3 \mathrm{~S} .7 \mathrm{HmbV}$ als Regelfall vorgesehen, der Tag einer Bürgerschafts- oder Bundestagswahl, muss zum einen die Mehrheit der Abstimmenden der Vorlage zustimmen (Abstimmungsmehrheit), zum anderen muss sie ein Zustimmungsquorum erreichen, das der Mehrheit der Hamburger Stimmen entspricht, die durch das gleichzeitig gewählte Parlament repräsentiert werden. Findet der Volksentscheid an einem anderen Tag statt (hierzu zählt auch der Tag einer Wahl zum Europäischen Parlament ${ }^{105}$ ), bleibt es bei der bisherigen Regelung: Erforderlich sind die Abstimmungsmehrheit und eine Zustimmungsmehrheit von mindestens $20 \%$ der Wahlberechtigten (Art. 50 Abs. 3 S. 13 HmbV).

Was sind nun die zu erwartenden praktischen Auswirkungen der neuen Quorenregelung? Für Verfassungsänderungen wird man sagen können, dass das bisherige prohibitiv wirkende starre Quorum von $50 \%$ der Stimmberechtigten ${ }^{106}$ gelockert wurde. Für Gesetzesentwürfe und andere Vorlagen dagegen wird die erforderliche Stimmenzahl im Regelfall deutlich erhöht. Zwei Beispiele: Zur Bürgerschaftswahl 2008 waren 1.237.397 Hamburgerinnen und Hamburger wahlberechtigt. Bei einer Wahlbeteiligung von 63,5\% entfielen auf die in der 19. Bürgerschaft vertretenen Parteien (nur diese sind „repräsentativ“ im Sinne von Art. 50 Abs. 3 HmbV) 721.187 Stimmen. Eine zeitgleich durchgeführte Volksabstimmung hätte unter Geltung der neuen Regelung ein Zustimmungsquorum von 480.791 für eine Verfassungsänderung bzw. von 360.594 Stimmen für ein Gesetz oder eine andere Vorlage zu überwinden gehabt. Dem stehen nach der alten Regelung 618.699 (Verfassungsänderung) bzw. 247.479 (Gesetz oder andere Vorlage) erforderliche Stimmen gegenüber. Legt man die Daten der Bundestagswahl 2005 zugrunde, fällt das Ergebnis noch deutlicher aus: 1.230.717 wahlberechtigte Hamburgerinnen und Hamburger verteilten 922.771 gültige Zweitstimmen auf die im 16. Bundestag vertretenen Parteien (Wahlbeteiligung: 77,5 \%). Eine gleichzeitig abzustimmende Verfassungsänderung hätte nach den neuen Regeln 615.181 (nach altem Recht 615.359) Stimmen, ein Gesetzesentwurf oder eine andere Vorlage 461.386 (bisher 246.143) Stimmen benötigt. Sieht man diese Zahlen hinsichtlich der Variablen (Wahlbeteiligung, Anzahl der ungültigen Stimmen, Anzahl der Stimmen für Parteien, die an der 5\%-Hürde scheitern) als grosso modo repräsentativ an, ergibt sich einzig für Verfassungsänderungen, über die am Tag von Bürgerschaftswahlen abgestimmt wird, eine spürbare Reduktion des Zustimmungsquorums. Dagegen erhöht sich die Zahl der erforderlichen Stimmen bei Volksabstimmungen über Gesetze oder andere Vorlagen deutlich - zeitgleich mit Bundestagswahlen fast auf das Doppelte.

Natürlich ist zu bedenken, dass Volksabstimmungen nach der Neuregelung vom Huckepack-Effekt profitieren und sich damit zugleich das Problem reduziert, dass nicht abgegebene Stimmen faktisch als Neinstimmen gewertet werden. ${ }^{107}$ Dennoch

105 Hamburgische Bürgerschaft, Drs. 19/1476, S. 5.

106 Dazu vertiefend v. Arnim, Schein (Fn. 6), S. 222-231.

$107 \mathrm{Zu}$ diesem Problem vertiefend und m.w.N. Jung, Grundsatzfragen (Fn. 14), S. 326-330; Neumann, Demokratie (Fn. 2), Rn. 783-791. 
ist die Erhöhung des Quorums signifikant. Tatsächlich wird bei den Abstimmungen über Gesetze und andere Vorlagen gerade keine „Waffengleichheit“ zwischen Volksgesetzgeber und Bürgerschaft hergestellt; denn trotz der veränderten Bezugsgröße liegt das Zustimmungsquorum nach Art. 50 Abs. 3 S. $10 \mathrm{HmbV}$ näher an einer absoluten Mehrheit als an den Regeln, nach denen Gesetzesbeschlüsse im Parlament zustande kommen (einfache Mehrheit der Anwesenden bei Beschlussfähigkeit). Angesichts dessen könnte dem Recht der Volksinitiatoren aus Art. 50 Abs. 3 S. $8 \mathrm{HmbV}$, eine Verschiebung des Volksentscheides zu beantragen, erhebliche Bedeutung zukommen. Es bleibt abzuwarten, ob sich dieser Weg etablieren wird. Art. 50 Abs. 3 S. $10 \mathrm{HmbV}$ könnte sich dann in der Praxis als weitgehend bedeutungslos erweisen.

\section{Die Abänderung vom Volk beschlossener Gesetze}

\section{a) Parlamentarische Konterlegislatur als Koordinationsproblem}

Die zweite markante und innovative Neuerung der Hamburger „Refolution“ ist von der Verfassungskrise der Jahre 2004-2007 geprägt, als die Bürgerschaft dem Verkauf des LBK zustimmte und das volksbeschlossene Wahlgesetz änderte. Das Problem der parlamentarischen Konterlegislatur ist viel diskutiert und kommentiert worden. ${ }^{108}$ Häufig, und letzten Endes fruchtlos, wird es dabei als eine Rangfrage behandelt. Wer im rousseauischen Überschwang den im volksbeschlossenen Gesetz zum Ausdruck kommenden Willen mit dem unverfälschten, urwüchsigen Volkswillen verwechselt, ${ }^{109}$ gelangt leicht zu einem Vorrang des Volksgesetzgebers und seiner Gesetze. Auch wenn diese Position heute nicht mehr offen vertreten wird, ${ }^{110}$ scheint sie doch hier und da durch, wenn von einem demokratischen „Mehrwert" plebiszitärer Demokratie die Rede ist. ${ }^{111}$ Ebenso wenig führt umgekehrt ein Vorrang des parlamentarischen Gesetzgebers weiter, der aufblitzt, wenn die reprä-

108 Siehe zuletzt Jung, Konterlegislatur (Fn. 31). Guter Überblick bei Momme Jacobsen, Zur Verbindlichkeit der Volksgesetzgebung, DÖV 2007, S. 949-960 (950-954).

109 Zu Recht kritisch Böckenförde, Demokratie (Fn. 102), S. 8-14; Luthardt, Probleme (Fn. 6), S. 15; Isensee, Verfahrensfragen (Fn. 55), S. 303 f., 312. Pointiert Claus Offe, Wider scheinradikale Gesten. Die Verfassungspolitik auf der Suche nach dem „Volkswillen“, in: Gunter Hofmann/Werner A. Perger (Hrsg.), Die Kontroverse: Weizsäckers Parteienkritik in der Diskussion, 1992, S. 126-142 (129): ,Der Volkswille besteht nicht vor diesen Verfahren und unabhängig von ihnen, sondern er entsteht in ihnen“ (Hervorhebungen im Original).

110 Tendenziell aber Decker, Demokratie (Fn. 2), S. 128 (,höherwertige Legitimität“). Zur Annahme eines rechtlichen Vorrangs in Teilen des Schrifttums in Weimarer Zeit Nachweise bei Franz-Josef Peine, Volksbeschlossene Gesetze und ihre Änderung durch den parlamentarischen Gesetzgeber, Der Staat 18 (1979), S. 375-401 (380-382); eingehende Kritik ebd., S. 383-395.

111 So z.B. v. Arnim, Schein (Fn. 6), S. 191, 193. Kritisch Uwe Berlit, Soll das Volk abstimmen? Zur Debatte über direktdemokratische Elemente im Grundgesetz, KritV 76 (1993), S. 318-359 (344 f.); Jung, Konterlegislatur (Fn. 31), S. 432 f. 
sentative Demokratie unter dem Grundgesetz als die „eigentliche“ Form der Demokratie bezeichnet wird. ${ }^{112}$

Letztlich dürfte heute in Deutschland weitgehend Einigkeit bestehen, dass Volksgesetzgeber und parlamentarischer Gesetzgeber gleichrangig sind. Nur ist mit einer solchen Erkenntnis für die Lösung des Problems der Konterlegislatur nicht viel gewonnen. Von diesem Ausgangspunkt aus wird z.B. für die Anwendung des lexposterior-Grundsatzes plädiert. ${ }^{113}$ Dieser bringt unvermeidlich das Parlament in die Vorhand, da das Volksgesetzgebungsverfahren zu schwerfällig ist, um schnell zu reagieren. ${ }^{114}$ Das Beispiel der Änderung und (letztlich freiwilligen) Rückänderung des HmbVAbstG in den Jahren 2005 und 2007 belegt dies. Es belegt auch, dass die politischen Kosten eines Abweichens nicht immer ausreichen, um auf eine faktische Bindungswirkung zu vertrauen. ${ }^{115}$ Umgekehrt wird auf Basis der Gleichrangigkeit aber auch für eine Änderungssperre plädiert, wie sie teilweise aus dem Kommunalrecht bekannt ist. ${ }^{116}$ Eine solche jedoch lässt sich ohne Anordnung im Verfassungstext nur schwer begründen; zudem kann sie sich bei notwendigen Änderungen als dysfunktional erweisen.

Überzeugender ist der Ansatz, den das Hamburgische Verfassungsgericht mit dem Grundsatz der Organtreue gewählt hat. ${ }^{117}$ Freilich hat das Gericht in der Anwendung dieses Grundsatzes dem regelmäßig oppositionellen Charakter des Volksgesetzgebungsverfahrens ${ }^{118}$ zu wenig Rechnung getragen und der Bürgerschaft allzu großzügig „Korrekturen“ durchgehen lassen. Dem spannungsreichen Verhältnis der beiden Gesetzgebungsorgane zueinander angemessener wäre der Rückgriff auf die clausula rebus sic stantibus, wonach erst bei einer Änderung der Sach- und Rechts-

112 Ernst-Wolfgang Böckenförde, Mittelbare/repräsentative Demokratie als eigentliche Form der Demokratie, in: FS für Kurt Eichenberger, 1982, S. 301-328. Siehe auch Isensee, Verfahrensfragen (Fn. 55), S. 304-307 („Prävalenz der parlamentarischen Gesetzgebung“).

113 So z.B. Martin Borowski, Parlamentsgesetzliche Änderungen volksbeschlossener Gesetze, DÖV 2000, S. 481-491 (489-491); Isensee, Plebiszit (Fn. 56), S. 112; ders., Verfahrensfragen (Fn. 55), S. 310; Rux, Demokratie (Fn. 2), S. 89 f. Grundsätzlich auch Matthias Rossi/SophieCharlotte Lenski, Treuepflichten im Nebeneinander von plebiszitärer und repräsentativer Demokratie, DVB1. 2008, S. 416-425 (418 f.).

114 HmbVerfG (Fn. 32), S. 311 - abw. Votum v. Paczensky und Wirth-Vonbrunn; Mahrenholz, Änderung (Fn. 29), S. 12-17; ders., Konkurrenzen (Fn. 29), S. 211-214. S. auch Krause, Möglichkeiten (Fn. 55), § 35 Rn. 47: „Verzögerungseffekt des Plebiszits“.

115 Zu dieser Luthardt, Probleme (Fn. 6), S. 21 f.; Engelken, Sperrwirkung (Fn. 91), S. 420. Als problematischer Nimbus charakterisiert von Isensee, Plebiszit (Fn. 56), S. 112; dems., Verfahrensfragen (Fn. 55), S. $310 \mathrm{f}$.

116 Markus Fritz/Peter Musall, Die Volksgesetzgebung im Freistaat Sachsen, SächsVB1. 2001, S. 233-238 (237) in analoger Anwendung von Art. 73 Abs. 2 SächsV, wonach ein abgelehnter Volksentscheid in der laufenden Legislaturperiode nicht noch einmal beantragt werden kann.

117 Dazu oben I.2.a. Im Ansatz zustimmend Mahrenholz, Konkurrenzen (Fn. 29), S. 215-217; Rossi/Lenski, Treuepflichten (Fn. 113), S. 422-425; Selmer, Gestaltung (Fn. 66), S. 193. In engen Grenzen auch Borowski, Änderungen (Fn. 113), S. 491.

118 v. Arnim, Schein (Fn. 6), S. 189 f.; Hartmann, Volksgesetzgebung (Fn. 82), S. 100; Mahrenholz, Konkurrenzen (Fn. 29), S. 214; Jung, Konterlegislatur (Fn. 31), S. 427. 
lage vom Votum eines Volksentscheides abgewichen werden darf. ${ }^{119}$ Dies ließe sich durchaus als Ausdruck des geschuldeten Interorganrespekts lesen. ${ }^{120}$ Erkennbar wird durch einen solchen Ansatz vor allem, dass Rangfragen nicht weiterführen, sondern dass es darum geht, zwei verschiedene Formen und Wege der Gesetzgebung aufeinander abzustimmen. ${ }^{121}$ Es geht um eine Koordinationsaufgabe, bei der die spezifischen institutionellen und funktionellen Charakteristika der beiden Gesetzgebungsorgane ebenso zu berücksichtigen sind wie das gleichberechtigte Recht beider, an der Definition des Gemeinwohls mitzuwirken, sofern die Verfassung einmal beide Wege der Gesetzgebung eröffnet hat. ${ }^{122}$

\section{b) Das „Hamburger Modell“: fakultatives Referendum}

Diesen koordinierenden Weg hat der verfassungsändernde Gesetzgeber in Hamburg weiterverfolgt, indem er das Problem der parlamentarischen Konterlegislatur auf prozedurale Weise aufgelöst hat. Das Volksgesetzgebungsverfahren wird für den Fall, dass die Bürgerschaft von einem volksbeschlossenen Gesetz abweichen will, um ein fakultatives Referendum ergänzt. Nach Art. 50 Abs. 4 HmbV tritt ein parlamentarisches Änderungsgesetz frühestens drei Monate nach Verkündung in Kraft. Verlangen innerhalb dieser Frist 2,5 \% oder mehr der Wahlberechtigten einen Volksentscheid über das Änderungsgesetz, tritt dieses erst nach Durchführung eines Referendums in Kraft. Das Referendum findet ebenfalls regelmäßig am Tag einer Bürgerschafts- oder Bundestagswahl statt, es sei denn, die Bürgerschaft beantragt einen abweichenden Termin (Art. 50 Abs. 3 S. 9). Für das Referendum gelten dieselben Quoren wie für die ursprüngliche Volksgesetzgebung (Art. 50 Abs. 4 S. 5).

Dieses Modell, das mit Ausnahme einer redaktionellen Änderung den Entwurf der Volksinitiative „Für faire und verbindliche Volksentscheide - Mehr Demokratie" wörtlich übernimmt, ist nicht ohne Vorbilder. ${ }^{123}$ So sah Art. 72 S. 1 WRV vor,

119 Peine, Volksbeschlossene Gesetze (Fn. 110), S. 399 f. m.w.N. auch zur Weimarer Debatte; Bull, Volksentscheid (Fn. 27), S. 100 f.; Jacobsen, Verbindlichkeit (Fn. 108), S. 958 f. Sympathisierend Jung, Konterlegislatur (Fn. 31), S. 440. Für eine Übernahme der US-amerikanischen Doktrin der clear and present danger Mahrenholz, Änderung (Fn. 29), S. 12 f.; ders., Konkurrenzen (Fn. 292008), S. 218.

120 Ähnlich schon Ramsauer/Heidmann, Wahlrecht (Fn. 28), S. 485. Grundlegend zu dieser Figur Ralph Alexander Lorz, Interorganrespekt im Verfassungsrecht, 2001.

121 Vgl. Peine, Volksbeschlossene Gesetze (Fn. 110), S. 398. Aus diesem Grunde führt auch der lex-posterior-Ansatz in die Irre, weil er eine Entscheidung über die Ermächtigung zur Rechtsänderung voraussetzt, die erst zu ermitteln ist: Erich Vranes, Lex Superior, Lex Specialis, Lex Posterior - Zur Rechtsnatur der „Konfliktlösungsregeln“, ZaöRV 65 (2005), 391-405 (397); Jung, Konterlegislatur (Fn. 31), S. 433 in Fn. 16.

122 Überzeugend Jacobsen, Verbindlichkeit (Fn. 108), S. 958 f.

$123 \mathrm{Zu}$ den Hintergründen instruktiv Jung, Konterlegislatur (Fn. 31), S. 434-440. Einen sehr ähnlichen Vorschlag hat 1979 bereits Peine, Volksbeschlossene Gesetze (Fn. 110), S. 398 f. auf Grundlage der Überlegung unterbreitet, dass es sich bei der Konterlegislatur um einen actus contrarius handele, der nur von demjenigen Organ legitimiert werden könne, das den zu korrigierenden Beschluss gefasst hat. 
die Verkündung eines Reichsgesetzes auf Antrag eines Drittels der Reichstagsabgeordneten um zwei Monate auszusetzen; in diesem Fall konnten nach Art. 73 Abs. 2 WRV 5 \% der Stimmberechtigten die Durchführung eines Volksentscheides beantragen. Dasselbe galt nach Art. 58 Abs. 1 HmbV von 1921, wenn 60 Abgeordnete die Aussetzung beantragten. Eine ähnliche Regelung findet sich heute noch in Art. 114 S. 1, 115 Abs. 1 RhPfV. Da hier indes - anders als nach Art. 50 Abs. 4 $\mathrm{HmbV}$ - die Initiative von einem Drittel der Abgeordneten ausging bzw. ausgeht, handelt es sich typologisch eher um „das Instrument einer starken parlamentarischen Opposition“124. Ein von der Initiative des Volkes abhängiges fakultatives Referendum kennt die Bundesverfassung der Schweiz (Art. 141 BV 1999); auch hier ist das Quorum gegenüber der Volksinitiative halbiert (50.000 Stimmberechtigte statt 100.000 gemäß Art. 139 BV). Anders als in Hamburg aber findet die Regelung nicht nur auf Gesetze Anwendung, die vom Volk beschlossene Gesetze ändern; zudem gibt es in der Schweiz keine vergleichbaren Zustimmungsquoren: nach Art. 142 Abs. $1 \mathrm{BV}$ entscheidet die Mehrheit der Abstimmenden.

Offen bleiben kleinere Fragen, die von der Verfassungspraxis beantwortet werden müssen. So ist unklar, wann genau von einer relevanten Änderung auszugehen ist. Franz-Josef Peine z.B. will die Abstimmungsbedürftigkeit nur bei Änderungen des eigentlichen Regelungsziels annehmen, nicht bei Änderung ,solcher Regelungen, die z.B. aus gesetzestechnischen Gründen, dem Volksentscheid muß ein vollständiger Gesetzesentwurf zugrunde liegen, erlassen worden sind““. ${ }^{125}$ Sofern es tatsächlich nur um technische Details geht, wird man dem aus pragmatischen Gründen vielleicht zustimmen können. Die Einschränkung auf das „,eigentliche Ziel“ der Regelung geht jedoch zu weit. Hier muss es den Abstimmenden überlassen bleiben, selbst über die Relevanz der jeweils zur Änderung anstehenden Regelung zu entscheiden. Von Art. $50 \mathrm{Abs} .4 \mathrm{HmbV}$ dürften ferner nur diejenigen Teile eines Gesetzes erfasst sein, die Änderungen gegenüber dem volksbeschlossenen Gesetz enthalten. ${ }^{126}$ Schließlich fragt sich, ob dem Recht der Bürgerschaft, nach Art. 50 Abs. 3 S. 9 HmbV eine Verlegung des Termins für das Referendum zu beantragen, eine Pflicht des Senates gegenübersteht, diesem Antrag zu entsprechen. Anders als im Fall eines Antrags der Volksinitiative (dazu oben 2.b.bb) lassen sich hier aus der Vorgeschichte der Norm keine Schlüsse ziehen.

\section{c) Änderung volksbeschlossener Gesetze durch den Volksgesetzgeber}

Das Volk selbst ist nach dem neuen Art. $50 \mathrm{HmbV}$ nicht länger daran gehindert, seine eigenen Gesetze zu ändern. Der alte Art. 50 Abs. 4, der eine Änderungssperre von zwei Jahren bestimmte, ist ersatzlos entfallen. Ob diese Sperre „bundesweit einzigartig“" war, ${ }^{127}$ mag angesichts immerhin verwandter Regelungen wie Art. 62

124 Jung, Konterlegislatur (Fn. 31), S. 437.

125 Peine, Volksbeschlossene Gesetze (Fn. 110), S. 400 f.

126 Vgl. Hamburgische Bürgerschaft, Drs. 19/1476, S. 5.

127 So Rux, Demokratie (Fn. 2), S. 822. 
Abs. 1 S. 2 BerlV oder Art. 73 Abs. 2 SächsV dahinstehen; jedenfalls ist ihr Wegfall zu begrüßen, da in der Tat nicht nachvollziehbar ist, „wieso das Volk über einen relativ langen Zeitraum an seine Entscheidung gebunden und daran gehindert sein soll, diese im Verfahren nach Art. 50 HambV zu korrigieren - während die Bürgerschaft es jederzeit in der Hand hat, das Ergebnis eines Volksentscheids durch eine entgegenstehende Entscheidung wieder aufzuheben“". ${ }^{28}$

\section{d) Verbindlichkeit von Volksentscheiden über ,, andere Vorlagen“}

Eine vor dem Hintergrund der vergangenen Konflikte wichtige Regelung trifft auch Art. 50 Abs. 4 a HmbV (die Aufnahme eines Absatzes „4a“ in eine von Grund auf umgestaltete Norm erscheint als regelungstechnisches Kuriosum). Dieser bestimmt nunmehr ausdrücklich die vom Hamburgischen Verfassungsgericht seinerzeit bestrittene Bindungskraft ,anderer Vorlagen“ (im Sinne von Abs. 1 S. 1), und zwar in doppelter Weise: Unter dem Aspekt der Geltung wird festgeschrieben, dass auch Volksentscheide über andere Vorlagen Bürgerschaft (!) und Senat binden; unter dem Aspekt der Fortgeltung werden die Regeln über die Änderung volksbeschlossener Gesetze für sinngemäß anwendbar erklärt. ${ }^{129} \mathrm{Da}$ es dem actus contrarius hier im Unterschied zur Gesetzgebung an Sichtbarkeit fehlen kann, ordnet Abs. 4 a S. 3 an, dass der Beschluss zur Aufhebung im Gesetz- und Verordnungsblatt zu verkünden ist.

\section{Die Konstitutionalisierung des Wahlrechts in Hamburg}

Den vorerst letzten Akt im „Refolutionstheater“ markieren die Änderungen zum Wahlrecht in Art. 6 Abs. 4 HmbV vom Juli 2009. Auch sie sind stark geprägt von den schweren Konflikten zwischen der 18. Bürgerschaft und den Volksinitiativen. Die eigenwilligen Neuregelungen lassen sich nur einordnen, wenn man sich die Vorgänge um die parlamentarische Korrektur des volksbeschlossenen Wahlrechts noch vor dessen erstmaliger Anwendung in Erinnerung ruft. Die Verfassungsänderung soll die jüngsten Absprachen zwischen der Bürgerschaft und den ehemaligen Volksinitiatoren absichern. Daher findet sie auch noch keine Anwendung auf die parallel vereinbarten Änderungen an den Wahlgesetzen, die sich noch auf dem parlamentarischen Weg befinden (vgl. Art. 2 des Änderungsgesetzes).

Nach der im systematischen Zusammenhang zu lesenden Regelung in Art. 6 Abs. 4 S. 2 bedürfen Gesetzesbeschlüsse der Bürgerschaft (ergänze: zum Bürgerschaftswahlrecht; Art. 4 Abs. 2 S. 3 erstreckt die Regelungen auch auf die Wahlen zu den Bezirksversammlungen) einer Mehrheit von zwei Dritteln der abgegebenen

128 Rux, Demokratie (Fn. 2), S. 846.

129 Zur Differenzierung dieser beiden Aspekte von Verbindlichkeit Klaas Engelken, Demokratische Legitimation bei Plebisziten auf staatlicher und kommunaler Ebene, DÖV 2000, S. 881-895 (883). 
Stimmen. Das Wahlrecht wird damit faktisch konstitutionalisiert. Nimmt man eine Stufung der Rechtsnormen anhand der Rechtserzeugungsregeln vor, ${ }^{130}$ sind die Wahlgesetze damit über die übrigen Gesetze gestellt, wenn sie auch noch unterhalb des ,eigentlichen“Verfassungsrechts rangieren, weil zwei Drittel der abgegebenen Stimmen genügen. Demgegenüber schreibt Art. 51 HmbV für Verfassungsänderungen im Wege der Parlamentsgesetzgebung zwei übereinstimmende Beschlüsse vor, zwischen denen ein Zeitraum von mindestens dreizehn Tagen liegen muss, und die beide bei Anwesenheit von drei Vierteln der gesetzlichen Mitgliederzahl mit einer Mehrheit von zwei Dritteln der anwesenden Abgeordneten gefasst werden müssen.

Die Wahlgesetze erhalten durch den neuen Art. 6 Abs. 4 HmbV nicht nur quasiverfassungsrechtlichen Status, sie erhalten auch den Status von Quasi-Volksgesetzen. Will die Bürgerschaft die Wahlgesetze ändern, finden die Bestimmungen zu Parlamentsgesetzen Anwendung, die volksbeschlossene Gesetze ändern sollen (dazu oben 3.b). Dies ist der Sache nach konsequent, wenn man bedenkt, dass die allerletzte Wahlrechtsnovelle zwar auf parlamentarischem Wege zustande gekommen ist, faktisch aber auf die Volksinitiative „Mehr Bürgerrechte - ein neues Wahlrecht für Hamburg“" zurückgeht, die den verwickelten (Um-)Weg durch die Institutionen genommen hat. Auch das Referendum über das parlamentarische Änderungsgesetz findet regelmäßig am Tag einer Bürgerschafts- oder Bundestagswahl statt; die Bürgerschaft kann eine Verlegung des Termins beantragen. Wird ein anderer Termin gewählt, schreibt Art. 6 Abs. 4 S. 3 HmbV eine Mehrheit von zwei Dritteln der abgegebenen Stimmen und eine Zustimmungsmehrheit von mindestens $20 \%$ der Wahlberechtigten vor - eine Kombination der alten Quoren für Gesetzesentwürfe (Zustimmungsquorum) und Verfassungsänderungen (Abstimmungsquorum). Findet das Referendum an einem der genannten Wahltage statt, gelten die neuen Bestimmungen für Volksentscheide zu Verfassungsänderungen entsprechend.

Das Wahlrecht ist nicht nur gegenüber Zugriffen des parlamentarischen Gesetzgebers besonders gesichert. Sein quasi-verfassungsrechtlicher Charakter kommt auch in einer erschwerten Abänderbarkeit durch den Volksgesetzgeber zum Ausdruck. Dieser muss zu einer Änderung des Wahlrechts die regulären Stufen (Volksinitiative, Volksbegehren) nehmen; im Volksentscheid gelten sodann die Quoren für Verfassungsänderungen. Außerdem ist verbindlich vorgeschrieben, dass der Volksentscheid am Tag einer Wahl zur Hamburgischen Bürgerschaft oder zum Deutschen Bundestag stattzufinden hat. Ein Recht, die Verlegung auf einen anderen Termin zu beantragen, steht den Volksinitiatoren ausdrücklich nicht zu.

130 Dazu Robert Walter, Der Aufbau der Rechtsordnung, 1964, S. 53-60; Theodor Schilling, Rang und Geltung von Normen in gestuften Rechtsordnungen, 1994, S. 401. 


\section{Kritische Würdigung}

\section{Verfassungsrechtliche Maßstäbe}

Dass auch Verfassungsänderungen an verfassungsrechtlichem Maßstab geprüft werden können, ist inzwischen fest verankert in der deutschen Verfassungskultur. Gerade Initiativen zur Stärkung der direkten Demokratie auf Landes- und Kommunalebene sind auch dann verschiedentlich an der restriktiven Rechtsprechung der Verfassungsgerichte gescheitert, wenn sie auf eine Änderung der Landesverfassung zielten. ${ }^{131}$ Das Hamburgische Verfassungsgericht hatte bislang weder Anlass noch Gelegenheit, zu den rechtlichen Grenzen Stellung zu nehmen, die einer Verfassungsänderung gesteckt sind. Angesichts bemerkenswerter Konvergenzen in der Verfassungsjudikatur der meisten anderen Bundesländer ${ }^{132}$ könnte diese erstaunlich homogene Rechtsprechung gleichwohl Orientierungswirkung besitzen. Eines freilich bleibt ungewiss: In vielen dieser Urteile scheint eine ,eher gefühlsmäßig anmutende Abwehrhaltung" gegen plebiszitäre Demokratie durch, ${ }^{133}$ die dadurch verstärkt worden sein könnte, dass ihnen sämtlich Volksbegehren zugrunde lagen, die eine Verfassungsänderung anstrebten. Mit anderen Worten: Es ist nicht auszuschließen, dass einer Stärkung der Volksgesetzgebung durch den parlamentarischen Verfassungsgesetzgeber (wie in Hamburg) mit größerer richterlicher Zurückhaltung begegnet würde als in einem Fall, in dem die Stärkung der Volksgesetzgebung ihrerseits im Wege der Volksgesetzgebung erfolgen soll.

Eine „Ewigkeitsgarantie“ wie in Art. 79 Abs. 3 GG ist der Hamburgischen Landesverfassung unbekannt. Dass der Zweite Senat des Bundesverfassungsgerichts in seiner Funktion als Landesverfassungsgericht für Schleswig-Holstein trotz ebenfalls fehlender „Ewigkeitsklausel“ ein verfassungsänderndes Gesetz ohne nähere Be-

131 Dazu kritisch bereits Przygode, Rechtsprechung (Fn. 86), S. 413: Tendenz zu einer „,,Verund Behinderungs'-Rechtsprechung“; ebenso Peter Neumann, Die Entwicklung der Rechtsprechung zu Volksbegehren und Volksentscheid nach der Deutschen Einheit, in: Schiller/ Mittendorf, Demokratie (Fn. 19), S. 115-152 (147): ,insgesamt als restriktiv zu bewerten“; vertiefend auch Wittreck, Verfassungsgerichtsbarkeit (Fn. 66), S. 111-185 zur Verteidigung der repräsentativen Demokratie durch die Landesverfassungsgerichte zwischen 2002 und 2005 (scharfe Kritik, v.a. auf S. 173-181: „Spekulation statt Folgenabschätzung“, ,,verweigerter Verfassungsvergleich“, „subkutane Geringschätzung der direkten Demokratie“). Vertiefend auch Engelken, Legitimation (Fn. 129), S. 881-895; Michael Sachs, Ewigkeitsgarantie für Grenzen der Volksgesetzgebung?, LKV 2002, S. 249-252; Jung, Probleme (Fn. 86), S. 442-444; ders., Schweizer Art (Fn. 99), S. 24-54; v. Arnim, Schein (Fn. 6), S. 253-257.

132 Vgl. Wittreck, Verfassungsgerichtsbarkeit (Fn. 66), S. 116: „Diese spezielle Form der intraföderalen Homogenität ist nicht allein durch Rezeptionsvorgänge unter den Gerichten zu erklären, sondern legt die Vermutung nahe, daß die einschlägige Rechtsprechung dem Rekurs auf ein vor- oder außerrechtliches Gesamtbild vom Verhältnis zwischen direkter und indirekter Demokratie geschuldet ist.“" Dazu auch näher ebd., S. 178-181.

133 Sachs, Ewigkeitsgarantie (Fn. 131), S. 250. 
gründung am Haushaltsvorbehalt in Art. 41 Abs. 2 SchlHV hat scheitern lassen, ${ }^{134}$ sollte man als bedauerliche Fehlentscheidung einordnen und nicht als Präjudiz für andere Fälle werten. Somit bleibt als Maßstab für eine Änderung der Landesverfassung nur Bundesrecht, Art. 31 GG (oder, theoretisch, Gemeinschaftsrecht). Grundsätzlich erkennt das Grundgesetz die Eigenstaatlichkeit der Länder und damit auch ihre Verfassungsautonomie an; von der verfassungsmäßigen Ordnung in den Länder verlangt Art. 28 Abs. 1 S. 1 GG lediglich, dass sie „,den Grundsätzen des republikanischen, demokratischen und sozialen Rechtsstaates im Sinne dieses Grundgesetzes entsprechen“ muss. Zudem muss nach S. 2 ,[i]n den Ländern, Kreisen und Gemeinden [...] das Volk eine Vertretung haben, die aus allgemeinen, unmittelbaren, freien, gleichen und geheimen Wahlen hervorgegangen ist". Das Bundesverfassungsgericht hat klargestellt, dass das Grundgesetz damit „,nicht Konformität oder Uniformität, sondern nur eine gewisse Homogenität durch Bindung an die leitenden Prinzipien herbeiführen“ will. ${ }^{135}$ Präzisierend hat es ergänzt: ,In diesen Bereich der Gestaltungsfreiheit der Länder, der weder durch Art. 28 Abs. 1 Satz 1 und 2 GG noch durch andere Vorschriften des Grundgesetzes beschränkt wird, gehören auch die landesrechtlichen Bestimmungen darüber, unter welchen Voraussetzungen und mit welchen Inhalten Volksbegehren und Volksentscheid zulässig sein sollen. " ${ }^{136}$ Man sollte sich daher davor hüten, die Ausformungen, die das Demokratieprinzip im Grundgesetz erhalten hat, zum Leitbild zu erheben und so die Verfassungsautonomie der Bundesländer zu unterminieren. Die Folge wären sechzehn Kopien des grundgesetzlichen Institutionengefüges, denen nur vereinzelte folkloristische Abweichungen gestattet wären. Umgekehrt liegt in der föderalen Vielfalt gerade die Chance, Erfahrungen zu sammeln und innovative Unruhe in das Gesamtsystem zu tragen. ${ }^{137}$

Das Grundgesetz selbst bestimmt in Art. 20 Abs. 2 S. 2, dass die Staatsgewalt vom Volk in Wahlen und Abstimmungen ausgeübt wird. Nun ist es kein Geheimnis, dass der politische Wille fehlte und nach wie vor fehlt, über die Neugliederung (Art. 29, 118) und die Ablösung der Verfassungsordnung (Art. 146) hinaus Plebiszite auf Bundesebene einzuführen; dass es hierfür auch gute sachliche Gründe gibt, soll hier nicht in Abrede gestellt werden. Zu warnen ist jedoch davor, den überdeutlichen Vorrang, den das parlamentarische System de constitutione lata auf Bundesebene genießt, auf Landesebene änderungsresistent abzubilden. Das Grundgesetz sieht Wahlen und Abstimmungen als Wege, den Volkswillen zu artikulieren. Auf Bundesebene ist von der Realisierung des zweiten Weges aus politischen Gründen bis-

134 BVerfGE 102, 176. Man könnte die Entscheidung allenfalls damit rechtfertigen, dass die Initiative nicht auf eine Änderung des Haushaltsvorbehalts selbst zielte, sondern auf eine (finanzwirksame) Änderung des Art. 8 (zu Schulfragen). Dies aber hätte näherer Ausführungen bedurft, die das Gericht schuldig geblieben ist.

135 BVerfGE 9, 268 (279); 27, 44 (56); 83, 37 (58); 90, 60 (84 f.).

136 BVerfGE 60, 175 (208).

137 Zu den Vorgaben des Homogenitätsgebotes für die direkte Demokratie in den Ländern näher Peter M. Huber, Die Vorgaben des Grundgesetzes für kommunale Bürgerbegehren und Bürgerentscheide, AöR 126 (2001), S. 165-203 (172-183); Neumann, Demokratie (Fn. 2), Rn. 652-657. 
lang so gut wie kein Gebrauch gemacht worden. Dies ist kein Präjudiz für die Landesebene. ${ }^{138}$

Ebenso wenig kann Art. 28 Abs. 1 S. 2 GG die Anordnung einer Präponderanz des Parlamentarismus entnommen werden. Dessen Normaussage beschränkt sich darauf, den Ländern gewählte Volksvertretungen vorzuschreiben. Damit sind zwar aus Sicht des Grundgesetzes Landesparlamente notwendige, Plebiszite fakultative Elemente der verfassungsmäßigen Ordnung in den Ländern; die Anordnung eines Rang- oder Gewichtsverhältnisses zwischen beiden Elementen - in Abweichung von der Verfassungshoheit der Länder - lässt sich dem nicht entnehmen. ${ }^{139}$ Schon rein tatsächlich ließe sich eine demokratische Ordnung in den Ländern ohne Parlamente nicht realisieren. Plebiszitäre Gesetzgebung ist zu schwerfällig und zu wenig auf politische Kontinuität ausgerichtet, um sich zur Steuerung von Gemeinwesen dieser Größe zu eignen. Sie kann damit immer nur Ergänzung des Parlamentarismus sein. ${ }^{140}$ Aus dieser faktischen Präponderanz eine rechtliche Prävalenz abzuleiten ${ }^{141}$ wäre jedoch ein naturalistischer Fehlschluss. ${ }^{142}$ Die soeben skizzierten Unterschiede rechtfertigen allerdings, unter funktionalen Gesichtspunkten vorsichtige Aussagen zur Verhältnisbestimmung zu treffen. Was nur das Parlament kann, muss auch dem Parlament vorbehalten bleiben. Die Volksgesetzgebung darf das Parlament bei der Wahrnehmung dieser Aufgaben auch nicht in unzumutbarer Weise behindern. ${ }^{143}$

\section{Einzelne Diskussionsfelder}

a) Verfassungsänderungsfester Haushaltsvorbehalt?

Die meisten landesverfassungsgerichtlichen Entscheidungen, die verfassungsändernde Volksbegehren anhielten, taten dies wegen Verstoßes gegen den Haushaltsvorbe-

138 Huber, Vorgaben (Fn. 137), S. 176-178.

139 Wittreck, Verfassungsgerichtsbarkeit (Fn. 66), S. 178 f. A.A. Walter Schmitt Glaeser, Grenzen des Plebiszits auf kommunaler Ebene, DÖV 1998, S. 824-831 (828 f.); Isensee, Vitalisierung (Fn. 95), S. 1167 f.; ders., Verfahrensfragen (Fn. 55), S. 304 f.; Selmer, Gestaltung (Fn. 66), S. 185 f. Tendenziell auch Huber, Vorgaben (Fn. 137), S. 184.

140 BayVerfGH, Entsch. v. 31.3.2000, Vf. 2-IX-00, DÖV 2000, S. 911-915 (911); BremStGH (Fn. 101), S. 917; Böckenförde, Demokratie (Fn. 102), S. 16; Krause, Möglichkeiten (Fn. 55), § 35 Rn. 27. So selbst v. Arnim, Schein (Fn. 6), S. 181 f. - Luthardt, Probleme (Fn. 6), S. 16, unterscheidet zwischen dem Parlamentarismus als „strukturgestaltendes Basisprinzip“ und direkter Demokratie als ,strukturgestaltendes Funktionselement“. Dazu, dass dies im Grunde unbestritten ist, Berlit, Volk (Fn. 111), S. $334 \mathrm{f}$.

141 So Isensee, Verfahrensfragen (Fn. 55), S. 307.

142 Ähnlich Platter, Haushaltsvorbehalt (Fn. 56), S. 506.

143 Vgl. Huber, Vorgaben (Fn. 137), S. 188; Neumann, Demokratie (Fn. 2), Rn. 654. Zur Funktionsfähigkeit der Parlamente als Grenze der Volksgesetzgebung auch Engelken, Legitimation (Fn. 129), S. 882 m.w.N. 
halt. ${ }^{144}$ Auch in der Literatur wird vertreten, der Ausschluss finanzwirksamer Plebiszite sei einer Verfassungsänderung entzogen. ${ }^{145}$ Wo eine landesverfassungsrechtliche Änderungssperre nicht zur Verfügung steht, wird auf Art. 28 Abs. 1 S. 1 GG (teilweise unter Heranziehung von Art. 79 Abs. 3 GG als Interpretationsleitlinie für das Homogenitätsminimum ${ }^{146}$ ) verwiesen, gelegentlich auch auf Art. 109 Abs. 2 GG. ${ }^{147}$ Hauptargumente für diese Lesart des Verfassungsrechts sind die Budgethoheit des Parlaments, der Gedanke der Funktionsgerechtigkeit sowie die Gemeinwohlorientierung, die nur im Prozess parlamentarischer Läuterung der Interessen zu garantieren sei. ${ }^{148}$ Wie bereits angedeutet, erweist sich letztlich nur das funktionale Argument als tragfähige Basis. Die Budgethoheit des Parlaments ist historisch vor allem aus dem Konflikt zwischen (monarchischer) Exekutive und Parlament gewachsen. Sie sichert den parlamentarischen Einfluss auf die Staatsleitung gegenüber der Gubernative und wird durch Volksgesetzgebung nicht gefährdet. Die Argumentation mit dem Gemeinwohl stellt einem Idealbild parlamentarischer Demokratie eine düster gefärbte ${ }^{149}$ „Realität“ direkter Demokratie gegenüber. ${ }^{150}$ Ausgeblendet wird, dass zwischen beiden Gesetzgebungsformen mehr Ähnlichkeiten bestehen als oft angenommen. ${ }^{151}$ Im gestuften Verfahren der Volksgesetzgebung, wie es Art. $50 \mathrm{HmbV}$ vorsieht, bestehen vielfältige Möglichkeiten, auf Anregungen und Kritik zu reagieren und Einigung mit dem Parlament zu suchen. Auf die Möglichkeit zur Überarbeitung des Entwurfs wird noch gesondert einzugehen sein.

Es bleibt das funktionelle Argument. Weithin unbestritten ist, dass der Haushaltsplan als solcher nicht sinnvoll auf plebiszitärem Wege verabschiedet werden kann. Das Haushaltsverfahren ist zu komplex und zu sehr auf Austarierung verschiedener Positionen angelegt, als dass es einer Volksgesetzgebung überantwortet werden könnte. Das Haushaltsgesetz selbst ist daher dem Parlament (im Zusammenspiel mit der Regierung) vorzubehalten. ${ }^{152}$ Nur das formelle Haushaltsgesetz

144 BremStGH (Fn. 101), S. 915 (dort nur LS 4, ausführlich NVwZ-RR 2001, S. 1-5 [4 f.]); BayVerfGH (Fn. 140), S. 911 (dort nur LS 3, ausführlich NVwZ-RR 2000, S. 401-406 [403]); ThürVerfGH (Fn. 58), S. 91-97; BVerfGE 102, 176 (185-191). Anders nur SächsVerfGH, Urt. v. 11.7.2002, Vf. 91-VI-01, NVwZ 2003, S. 472-476. Zu dieser Rechtsprechung kritisch Rux, Haushaltsvorbehalte (Fn. 61), S. 256 f. Eingehend Wittreck, Verfassungsgerichtsbarkeit (Fn. 66), S. 116-132, 136 f., 144 f., 165-168, 170-173.

145 Isensee, Vitalisierung (Fn. 95), S. 1161-1165; ders., Plebiszit (Fn. 56), S. 126 f.; Selmer, Gestaltung (Fn. 66), S. $190 \mathrm{f}$.

146 Sebastian Müller-Franken, Plebiszitäre Demokratie und Haushaltsgewalt, Der Staat 44 (2005), S. 19-42 (20); Isensee, Verfahrensfragen (Fn. 55), S. 305 f.

147 BremStGH (Fn. 101), S. 915 (dort nur LS 4, ausführlich NVwZ-RR 2001, S. 1-5 [4f.]); Selmer, Gestaltung (Fn. 66), S. 192.

148 Statt aller Isensee, Plebiszit (Fn. 56), S. 104-111.

149 Auf alles in allem positive Erfahrungen aus den USA und der Schweiz verweist Rux, Haushaltsvorbehalte (Fn. 61), S. 254.

150 Rux, Haushaltsvorbehalte (Fn. 61), S. 254; ähnlich Sachs, Ewigkeitsgarantie (Fn. 131), S. 251. Kritisch auch v. Arnim, Schein (Fn. 6), S. 185 f., 290-299.

151 Zu diesen näher Jacobsen, Verbindlichkeit (Fn. 108), S. 955-958.

152 Platter, Haushaltsvorbehalt (Fn. 56), S. 506; Isensee, Plebiszit (Fn. 56), S. 107 f.; Selmer, Gestaltung (Fn. 66), S. 189 f. Näher Müller-Franken, Haushaltsgewalt (Fn. 146), S. 33-38. 
auszunehmen, würde indes die Gefahr in sich bergen, dass finanzwirksame Volksgesetze Parlament und Regierung bei der Haushaltsplanung übermäßig behindern. Der funktionelle Gedanke ist aber nicht nur ein formal-technischer; da das Parlament ebenso wie der Volksgesetzgeber „Volkes Stimme“ repräsentiert, muss auch dem Verantwortungsgedanken Rechnung getragen werden, d.h. das Parlament hat den Gesamthaushalt zu verantworten. ${ }^{153}$ Hat ein Volksgesetz wesentliche Auswirkungen auf die Staatsfinanzen, kann die Möglichkeit eines parlamentarisch verantworteten Haushalts gefährdet sein. ${ }^{154}$ Es erscheint zu eng, die Grenze dort zu ziehen, wo das Parlament nicht mehr in der Lage ist, einen verfassungskonformen Haushalt vorzulegen; ${ }^{155}$ dies würde einem Verantwortungsgedanken, der eigene politische Entscheidungen impliziert, nicht gerecht. Die parlamentarische Gestaltungsmacht würde hier zwischen den Zwängen heteronomer politischer Entscheidungen und des Haushaltsverfassungsrechts aufgerieben. ${ }^{156}$ Es kann aber auch umgekehrt nicht schon jede Haushaltsbelastung im Promillebereich als „wesentlich“ ausgegeben werden. Bei einer Gesamtwürdigung sind absolute und relative Höhe der Ausgaben (bzw. Mindereinnahmen) ebenso zu berücksichtigen wie deren Art und Dauer und die aktuelle Haushaltslage. ${ }^{157}$ Dem Parlament können Umschichtungen im Haushalt durchaus zugemutet werden. ${ }^{158}$ Deckungsvorschläge der Volksinitiatoren, wie sie nach $\S 3$ Abs. 2 HmbVAbstG vorgelegt werden sollen, können hilfreich sein, sind aber nicht zwingend geboten. ${ }^{159}$ Da das Parlament den Haushalt am Ende verantworten soll, muss es auch selbst die Entscheidung treffen, wie die volksbeschlossene Maßnahme finanziert wird.

Eine Beschränkung des Haushaltsvorbehalts allein auf den Haushaltsplan im formellen Sinne kann demnach auch durch eine Verfassungsänderung nicht erreicht werden. ${ }^{160}$ Dies wird das Hamburgische Verfassungsgericht bei der Auslegung des neuen Art. 50 Abs. 1 S. 3 HmbV zu berücksichtigen haben. ${ }^{161}$

153 Birk/Wernsmann, Finanzen (Fn. 72), S. 672. So auch Isensee, Plebiszit (Fn. 56), S. 106 f.

154 Zur Wesentlichkeitsgrenze auch Birk/Wernsmann, Finanzen (Fn. 72), S. 672; Rux, Haushaltsvorbehalte (Fn. 61), S. 254; Isensee, Plebiszit (Fn. 56), S. 118, 125; Müller-Franken, Haushaltsgewalt (Fn. 146), S. $40 \mathrm{f}$.

155 So SächsVerfGH (Fn. 144), S. 472 LS 3, S. 475 f.

156 Isensee, Plebiszit (Fn. 56), S. 107; Müller-Franken, Haushaltsgewalt (Fn. 146), S. 38-40.

157 Birk/Wernsmann, Finanzen (Fn. 72), S. 672 f.; Müller-Franken, Haushaltsgewalt (Fn. 146), S. 41.

158 Rux, Haushaltsvorbehalte (Fn. 61), S. 255. Anders wohl Müller-Franken, Haushaltsgewalt (Fn. 146), S. 41.

159 Vertiefend zum Deckungsjunktim Krafczyk, Finanzvorbehalt (Fn. 66), S. 297-319 (Realisierbarkeit), 319-341 (Zulässigkeit).

160 Dazu noch einmal eingehend Krafczyk, Finanzvorbehalt (Fn. 66), S. 223-291.

161 Eine solche bundesverfassungskonforme Interpretation hält Selmer, Gestaltung (Fn. 66), S. 192 allerdings für ausgeschlossen. 


\section{b) Sicherung eines ausreichenden Legitimationsniveaus}

Dass Volksgesetzgebung nicht darin bestehen kann, dass eine kleine Gruppe von Aktivisten sich als das Volk ausgibt und allgemeinverbindliche Gesetze beschließt, liegt auf der Hand. ${ }^{162}$ Wie das Verfahren der Parlamentswahl auch, muss das Volksgesetzgebungsverfahren Vorkehrungen treffen, um sicherzustellen, dass die Chance besteht, in der getroffenen Entscheidung eine Manifestation des Volkswillens zu erblicken. Dabei impliziert Repräsentation freilich immer auch, dass die Aktivbürger diejenigen mit-repräsentieren, die ihr Recht zu Passivität ${ }^{163}$ nutzen und nicht an der Wahl oder an der Abstimmung teilnehmen. ${ }^{164}$ So besehen ist die Teilnahme keine Pflicht, aber gewissermaßen Obliegenheit: Wer nicht teilnimmt, darf sich am Ende nicht beklagen. Unfair (und schon gar nicht verfassungsänderungsfest vorgegeben) erscheint es, das Risiko der Nichtbeteiligung allein bei der Volksgesetzgebung zu Lasten der Volksinitiatoren gehen zu lassen, während bei Wahlen de jure ein einziger Wähler genügen würde, ein gültiges Ergebnis zu produzieren. ${ }^{165}$ Natürlich sollten (rechtliche) Repräsentation und (faktische) Repräsentativität nicht allzu weit auseinanderklaffen; die letzte Entscheidung über die Beteiligung liegt aber immer beim Bürger. Eine hinreichende Legitimation für demokratische Entscheidungen zu beschaffen, ist nicht allein eine Frage von Abstimmungsquoren, die überdies eine deutsche Spezialität darstellen; ohne ein gerüttelt Maß an Rechtserfindung wird man Art. 28 Abs. 1 GG keine bestimmten Quoren für Volksentscheide in den Ländern entnehmen können. ${ }^{166}$ Notwendig ist vielmehr eine Gesamtbewertung des Verfahrens.

Das dreistufige Verfahren des Art. $50 \mathrm{HmbV}$ beinhaltet eine schrittweise Qualifikation, bei der von Stufe zu Stufe mit wachsender Verbindlichkeit auch höhere Hürden zu überwinden sind. Das gestufte Verfahren sorgt im Übrigen auch für eine Generierung von Aufmerksamkeit: Eine gewisse Interessiertheit vorausgesetzt, sieht man, was auf einen zukommen soll. Die gegenüber dem Volksentscheid vom September 1998 deutlich ausgebauten Informationspflichten tragen zur staatsbürgerlichen Involviertheit aller bei. Nicht unproblematisch ist allerdings das in Art. 50 Abs. 2 und $3 \mathrm{HmbV}$ den Volksinitiatoren zugebilligte Recht zur Überarbeitung ihres Entwurfs, da es den Legitimationszusammenhang zwischen den einzelnen Stufen des Volksgesetzgebungsverfahrens durchbricht und den Initiatoren eine legislatori-

162 Zu dieser Grundbefürchtung Engelken, Legitimation (Fn. 129), S. 882 f.: Es müsse verhindert werden, „daß eine verschwindend geringe Zahl von interessierten aktiven Bürgern für die Gesamtheit verbindliches Recht setzt".

163 Dazu z.B. Huber, Vorgaben (Fn. 137), S. 179.

164 Horst Dreier, Landesverfassungsänderung durch quorenlosen Volksentscheid, BayVB1. 1999, S. 513-523 (520).

165 Berlit, Volk (Fn. 111), S. 356. Vgl. auch Wittreck, Verfassungsgerichtsbarkeit (Fn. 66), S. 183. Eine kategoriale Unterscheidung dagegen nehmen u.a. Engelken, Legitimation (Fn. 129), S. 884-886 und Isensee, Vitalisierung (Fn. 95), S. $1166 \mathrm{f}$. (unter Berufung auf ein „rechtsethisches“ Gefälle) vor.

166 Huber, Vorgaben (Fn. 137), S. 180. 
sche Vorhand zugesteht. ${ }^{167}$ Da aber Grundcharakter und (Teil-)Ziele unverändert zu bleiben haben und der überarbeitete Entwurf sich der Abstimmung zu stellen hat, bestehen keine durchgreifenden Einwände. ${ }^{168}$ Für das Hamburger Volksgesetzgebungsverfahren trifft also nicht länger zu, dass die Entwürfe im Volksgesetzgebungsverfahren ,unverrückbar“ sind. Damit entfällt zugleich ein Haupteinwand gegen die Rationalität des Verfahrens, nämlich dessen (angebliche) Korrekturunfähigkeit. ${ }^{169}$

Dass eine Reihe von Volksinitiativen in Hamburg wegen zu geringer Beteiligung nicht die Stufe zum Volksbegehren nehmen konnte, ${ }^{170}$ zeigt, dass der Aktionismus eines kleinen Häufchens Entschlossener keineswegs genug ist, um das Volksgesetzgebungsverfahren anzustoßen. Die Hamburger Quoren für Volksinitiative und Volksbegehren sind sicherlich eher auf Ermöglichung, denn auf Verhütung des Erfolges gerichtet; doch dies ist eine Entscheidung, die ein Verfassungsgesetzgeber in seinem Bereich treffen können muss. Sie sind auch im Rechtsvergleich nicht ungewöhnlich niedrig. ${ }^{171}$ Auf Ebene des Volksbegehrens birgt die nunmehr verfassungskräftig garantierte Möglichkeit zur freien Listensammlung zwar gewisse Probleme (oben II.2.b.aa); sie schlagen aber letztlich nicht durch, zumal das Volksbegehren nur eine Zwischenstufe darstellt und nicht zu verbindlichen Beschlüssen führt. Dass die freie Stimmensammlung dem Gedanken widerspreche, ,daß die Akte der Volksgesetzgebung [...] eine der Parlamentsgesetzgebung vergleichbare Dignität aufweisen müssen“"172, lässt sich auch mit bestem Willen nicht als verfassungsänderungsfester Maßstab aus Art. 28 Abs. 1 GG destillieren. Die daneben eröffnete Möglichkeit zur Briefeintragung ermöglicht eine informierte Entscheidung ohne äußere Zwänge und ist daher einschränkungslos zu begrüßen.

Die Quoren für den Volksentscheid sind durch Art. 50 Abs. 3 HmbV n.F. nur für Verfassungsänderungen reduziert (und auch dies nur unter bestimmten Voraussetzungen). Auch wenn man anerkennt, dass für Verfassungsänderungen über die Abstimmungsmehrheit hinaus Beteiligungs- oder Zustimmungsquoren unerlässlich sind, weil die Verfassung dem Gemeinwesen eine gewisse Stabilität und Dauerhaftigkeit vermitteln und sich auf eine möglichst breite Legitimationsbasis stützen soll, ${ }^{173}$ sind die Quoren weit davon entfernt, Bedenken zu erregen. Selbst die nicht

167 Scharfe Kritik übt Isensee, Verfahrensfragen (Fn. 55), S. 321-323 (Umgehung des Unterschriftenquorums). Vgl. auch SaarlVerfGH, Urt. v. 14.7.1987, Lv 3/86, NVwZ 1988, S. 245-249 (247 f.).

168 Vgl. Stüber, Volksabstimmungen (Fn. 24), S. $231 \mathrm{f}$.

$169 \mathrm{Zu}$ diesem Einwand Isensee, Plebiszit (Fn. 56), S. 114.

170 Vgl. Übersicht unter http://hh.mehr-demokratie.de/3099.html (aufgerufen am 6. September 2009).

171 Für die rechtsvergleichende Methode zur Bestimmung ,struktureller Kongruenz“ im Rahmen von Art. 28 Abs. 1 GG Huber, Vorgaben (Fn. 137), S. 174 f.

172 BayVerfGH (Fn. 140), S. 914. Mit Recht kritisch Wittreck, Verfassungsgerichtsbarkeit (Fn. 66), S. $149 \mathrm{f}$.

173 BayVerfGH, Entsch. v. 17.9.1999, Vf. 12-VIII-98 u.a., BayVBl. 1999, S. 719-727 (723 f.); BayVerfGH (Fn. 140), S. 911 f. Zustimmend Engelken, Legitimation (Fn. 129), S. 881; Huber, Vorgaben (Fn. 137), S. 181; Alfred Rinken, Volksgesetzgebung und Verfassung, in: FS für Alexander Hollerbach, 2001, S. 403-425 (419-422). Siehe auch Berlit, Volk (Fn. 111), 
sonderlich überzeugende $25 \%$-Marke, die der Bayerische Verfassungsgerichtshof der Landesverfassung zu extrahieren vermochte, ${ }^{174}$ wäre, wie die Beispielsrechnungen zeigen, unter den Bedingungen der üblichen Wahlbeteiligung klar gewahrt. Sollte die Wahlbeteiligung so drastisch absinken, dass ein Zustimmungsquorum von $25 \%$ unterschritten würde, wäre dies eine Krise der Demokratie, die auch und vor allem den Parlamentarismus erfasst. Hierin liegt ja gerade der besondere Charme des Hamburger Modells, dass es das Legitimationsniveau des Volksentscheides an das der Wahlen koppelt. Jede ,parlamentaristische“ Kritik an der mangelnden Legitimation eines Volksentscheides kehrt sich so gegen sich selbst. Zwar wird das Modell, wie dargelegt, nicht konsequent durchgeführt (oben II.2.b.cc); der Verfassungsjurist ist aber gut beraten, einen mühsam errungenen Kompromiss nicht durch ein zweifelhaftes und überzogenes Folgerichtigkeitsgebot zu behindern. ${ }^{175}$ Die Konzeption ist zumindest im Großen und Ganzen erkennbar und plausibel und damit jedenfalls nicht willkürlich in einem Sinne, der selbst dem verfassungsändernden Gesetzgeber Fesseln anlegte. ${ }^{176}$ Für einfache Gesetze und andere Vorlagen sind durch die Neufassung von Art. 50 Abs. $3 \mathrm{HmbV}$ die Quoren sogar deutlich erhöht worden. Dem Verfassungsgesetzgeber steht auch diese Entscheidung rechtlich frei. Verfassungspolitisch allerdings sind Zweifel angebracht, ob das Quorum hier nicht unangemessen hoch angesetzt worden ist. Dass die beabsichtigte Synchronisierung des Legitimationsniveaus parlamentarischer und plebiszitärer Beschlüsse damit gerade nicht verwirklicht wurde, ist oben bereits zur Sprache gekommen (II.2.b.cc).

Nicht ersichtlich ist schließlich, warum die regelmäßige Kopplung von Volksentscheiden an Wahltage nicht nur dem Gesetzgeber, sondern sogar dem Landesverfassunggeber untersagt sein soll. ${ }^{177}$ Gewiss gibt es Argumente für und wider eine solche Kopplung: Dem Huckepack-Effekt steht die ebenfalls bereits erwähnte Gefahr einer parteipolitischen Instrumentalisierung gegenüber, um nur zwei der Hauptpunkte zu nennen. Letztlich ist es dem Wahl- bzw. Stimmbürger durchaus zuzutrauen, zwischen der Wahlentscheidung und dem Volksentscheid zu differenzieren. Sollte ihm die Sachfrage, über die im Volksentscheid abgestimmt wird, so wichtig sein, dass seine Sympathien auch bei der Wahl derjenigen Partei gehören, die den Entwurf unterstützt, ist auch dies eine freie Entscheidung, die es zu respektieren gilt.

S. 357. Kritisch Dreier, Landesverfassungsänderung (Fn. 164), S. 513-523; Jung, Schweizer Art (Fn. 99), S. 40-46.

174 BayVerfGH (Fn. 173), S. 725. Ebenso wenig überzeugend Hans-Detlef Horn, Mehrheit im Plebiszit, Der Staat 38 (1999), S. 399-422 (419-421), der zwischen dem demokratietheoretisch ,eigentlich“ gebotenen Quorum von $50 \%$ und dem Recht der Abstimmenden auf Passivität ,praktische Konkordanz" mit dem Taschenrechner herstellt und, natürlich, $25 \%$ errechnet. Dem zaghaft folgend Engelken, Legitimation (Fn. 129), S. 887-889 (,,auf der sicheren Seite“). Noch weitergehend freilich Isensee, Vitalisierung (Fn. 95), S. 1168 f.: Selbst ein verfassungsänderndes Zustimmungsquorum von $25 \%$ in der Landesverfassung sei unvereinbar mit Bundesrecht.

175 So zweifelhaft zuletzt BVerfGE 121, 317 (377 f.).

$176 \mathrm{Zu}$ diesem Maßstab bereits für den einfachen Gesetzgeber überzeugend BVerfGE 121, 317 (378-381) - abw. Votum Bryde.

177 So aber nachdrücklich Isensee, Vitalisierung (Fn. 95), S. 1169 f. 
Von einem „Freibrief zur Manipulation“178 kann nicht die Rede sein, auch nicht, weil des regelmäßig oppositionellen Charakters der Volksgesetzgebung wegen von einem solchen Mitnahmeeffekt wohl eher Oppositionsparteien profitieren würden. Auch dem Entwurf einen ,zumindest amtsähnlichen Charakter“ zu attestieren, „weil ein Gesetzesvorschlag [...] mehr ist als ein Akt privater Grundrechtsausübung"179, stützt den Manipulationsvorwurf nicht. Die Autoren der Vorlage sind als solche gekennzeichnet, und in Hamburg (wie auch anderswo) steht es dem Landesparlament frei, einen konkurrierenden Entwurf vorzulegen. Wer also Sach- wie Personalentscheidung allein daran orientiert, wie ,amtlich“ das Angebot sich präsentiert, dem bleibt es unbenommen, allein beim Parlamentsvorschlag „Ja“ anzukreuzen und seine Stimme als Wähler denjenigen Parteien und Bewerbern zu geben, welche die amtierende Regierung unterstützen. Begegnen die genannten Einwände also schon auf rechtspolitischer Ebene Zweifeln, ist mit ihnen erst recht keine Hürde zu begründen, an denen der Verfassungsgesetzgeber scheitern könnte.

\section{c) Hürden bei der Änderung vom Volk beschlossener Gesetze}

Die neuen Regelungen zur Abänderung vom Volk beschlossener Gesetze oder anderer Vorlagen in Art. 50 Abs. 4 und 4 a HmbV erscheinen vom Ansatz her gelungen, zumal sie das Problem der parlamentarischen Konterlegislatur konsequent als Koordinationsproblem begreifen und angehen. Das Modell fügt sich stimmig in das Grundkonzept einer Volksgesetzgebung ein und eröffnet keinen Weg neben dieser, wie z.B. in der Schweizerischen Bundesverfassung. Es geht letztlich nur um die Sicherung gegen einen allzu großzügigen Umgang der Bürgerschaft mit den Ergebnissen von Volksentscheiden. Dass die Hürde niedrig angesetzt ist, ist angesichts der Dringlichkeit nachvollziehbar. Überdies könnte bei einem Quorum von 5\%, das zuvor diskutiert wurde, gleich eine neue Volksinitiative gestartet werden. ${ }^{180}$ Da das zu ändernde Gesetz bereits die qualifizierte Zustimmung des Volkes im Volksentscheid erhalten hat, bestehen auch keine verfassungsrechtlichen Bedenken, dass einer Sperrminorität von nur 2,5\% ein suspensives Vetorecht an die Hand gegeben wird. ${ }^{181}$ Verfassungspolitisch wird man das Modell erst beurteilen können, wenn es zu ersten Anwendungsfällen gekommen ist.

Unglücklich erscheint freilich, dass keine Regelung für dringliche Fälle aufgenommen wurde. Eine solche fand sich in Art. 72 S. 2 WRV und findet sich noch in Art. 114 S. 1 RhPfV. Dass alle Änderungsgesetze im Sinne von Art. 50 Abs. 4 HmbV frühestens drei Monate nach Verkündung in Kraft treten können, könnte sich bei dringendem Änderungsbedarf als kontraproduktiv erweisen. Da der Träger des Initiativrechts nicht persönlich benennbar ist, gibt es auch keine Möglichkeit, auf das suspensive Veto vor Ablauf der drei Monate wirksam zu verzichten. Hier hätte es

178 Isensee, a.a.O.

179 Isensee, Vitalisierung (Fn. 95), S. 1170.

180 Jung, Konterlegislatur (Fn. 31), S. 435.

181 Anders wohl Selmer, Gestaltung (Fn. 66), S. 192 f. 
näher gelegen, der Bürgerschaft das Recht einzuräumen, ein Gesetz für dringlich zu erklären und im Streitfall die verfassungsgerichtliche Überprüfung zuzulassen. Dass eine solche Ausnahmevorschrift fehlt, ist bedauerlich, aber kein Grund, verfassungsrechtliche Kritik an einer Verfassungsänderung zu üben. Sollte das Problem überhaupt einmal relevant werden, wird man nach pragmatischen Lösungen suchen müssen.

\section{Abschließende Würdigung}

Die Hamburger Volksgesetzgebung hat mit den jüngsten Reformen einen großen Satz nach vorn getan und ist auf einem spannenden, teils auf einem guten Weg. Mit den Regelungen zu den Abstimmungsquoren und zur Abänderung von Volksentscheiden liegen bundesweit einmalige Modelle vor, ${ }^{182}$ die ihren Praktikabilitätstest noch vor sich haben, aber immerhin neue Optionen in ein weithin abgesteckt scheinendes Feld einführen. Es ist im Rückblick ironisch, dass diese nachdrückliche Stärkung der plebiszitären Demokratie zu einem guten Teil dadurch begünstig wurde, dass der CDU-Senat ab 2004 den Bogen auch aus Sicht jener überspannt hatte, die direkter Demokratie eher leidenschaftslos gegenüberstehen. Die zentralen Streitpunkte jener Jahre - Abstimmungsquoren, freie Listeneintragung, Abstimmungstage und die Verbindlichkeit von Volksentscheiden - sind jetzt gelöst. Ob in richtiger oder falscher Weise, mag jeder nach seinen Vorlieben entscheiden; jedenfalls sind sie in verfassungskonformer Weise gelöst.

Manche handwerkliche Unsauberkeiten werden noch zu korrigieren sein; auch eine Anpassung des HmbVAbstG scheint unausweichlich. Sind diese Kinderkrankheiten aber erst einmal überwunden, sieht die doppelgleisige Gesetzgebung in Hamburg interessanten Zeiten entgegen. Gerade ein Stadtstaat kann sich als Experimentierfeld für Formen direkter Demokratie empfehlen: ${ }^{183}$ Die Bevölkerung wohnt dichter beisammen, was den Grad der Betroffenheit erhöht; die Themen sind auch räumlich „näher“ an den Menschen als in einem Flächenstaat; die Bürger sind im Allgemeinen besser mobilisierbar. Der Durchgang durch die „neue“ Hamburger Volksgesetzgebung, der hier unternommen wurde, sollte belegen, dass es nicht immer nur der Blick ins Ausland sein muss. Auch Hamburg wird nach der jüngsten „Refolution“ für einschlägige Rechts- und Systemvergleiche ein lohnender Bezugspunkt sein.

182 Nicht unähnlich der am 27. August 2009 mit knapper verfassungsändernder Mehrheit beschlossene neue Art. 73 Abs. 2 BremV, der innerhalb einer Sperrfrist von zwei Jahren Änderungen volksbeschlossener Gesetze auf drei Wegen gestattet: durch die Bürgerschaft mit verfassungsändernder Mehrheit, durch ein von der Bürgerschaft initiiertes Referendum oder durch einen neuerlichen Volksentscheid.

183 Bull, Demokratie (Fn. 90), S. 16-37; Rux, Demokratie (Fn. 2), S. 845. 